\title{
LOS CANALES DE LAS MÉDULAS (LEÓN-ESPAÑA): RAZONES PARA SU INCLUSIÓN EN EL PATRIMONIO DE LA HUMANIDAD
}

\author{
The Canals of Las Médulas (León-Spain): Reasons \\ for its Inclusion in the World Heritage
}
Os canais de Las Médulas (León-Espanha): motivos para sua inclusão no Patrimônio Mundial

\author{
Roberto MATÍAS RODRÍGUEZ \\ Ingeniero de minas. \\ Correo:
}

Fecha de recepción: 3/01/2021

Fecha de aceptación: 13/01/2021

RESUMEN: La declaración en 1997 de la explotación aurífera romana de Las Médulas como Patrimonio de la Humanidad supuso un merecido reconocimiento a la mayor explotación minera del Mundo Antiguo. Sin embargo, esta declaración pasó por alto el conjunto de esta magnífica obra de ingeniería, centrándose únicamente en el singular paraje de picachos rojos, residuos de los trabajos de extracción. De este modo, quedaron al margen los canales de abastecimiento de agua, imprescindibles para poder realizar el derrumbe de la montaña, sistema que el naturalista romano Plinio denomina arrugia, y permitir la recuperación del oro en los canales de lavado. En ese momento, parece ser que los canales fueron considerados como una obra menor y se encontraban muy escasamente documentados, con la carencia absoluta de una topografía adecuada, a pesar de ser ampliamente conocidos por los naturales de la zona. No es hasta el año 2004 cuando se publica la primera cartografía de detalle, que arroja ya la sorprendente cifra de $600 \mathrm{~km}$ de canales, sucesivamente ampliados con nuevas investigaciones y hallazgos en el 2008 y 2017, por lo que se alcanzan ya los $700 \mathrm{~km}$ de recorrido. A las Médulas llegaban algunos 
ROBERTO MATÍAS RODRÍGUEZ

LOS CANALES DE LAS MÉDULAS (LEÓN-ESPAÑA): RAZONES PARA SU INCLUSIÓN EN EL PATRIMONIO...

canales de 147 y $124 \mathrm{~km}$, que corroboran las cifras de cien millas que menciona Plinio. Este último canal realizó un importante trasvase de aguas de la Cuenca del Duero a la Cuenca del Sil. La estructura de abastecimiento desvela la existencia de distintas fases de trabajo en el yacimiento aurífero y un detalle muy importante: la explotación se interrumpió por agotamiento. La magnitud de esta obra de ingeniería, imprescindible para la existencia de las propias Médulas, no puede pasar desapercibida, y sin duda merece el reconocimiento homónimo que ya ha recibido el objeto para el que fue construido.

Palabras clave: canales romanos; ingeniería romana; Las Médulas; minería oro romana.

ABSTRACT: The declaration in 1997 of the Roman gold exploitation of Las Médulas as a World Heritage Site was a well-deserved recognition of the largest mining exploitation in the Ancient World. However, this statement overlooked the entirety of this magnificent engineering work, focusing solely on the unique spot of red peaks, residues of the extraction works. In this way, the water supply canals, essential to carry out the collapse of the mountain, a system that the Roman naturalist Pliny calls "arrugia", and the recovery of gold in the washing canals, were left out.

At that time, it seems that the canals were considered a minor work and were very scarcely documented, with the absolute lack of adequate topography, despite being widely known to the natives of the area. It was not until 2004 when the first detailed cartography was published, which now shows the surprising figure of 600 $\mathrm{km}$ of canals, successively expanded with new research and findings in 2008 and 2017, for which the $700 \mathrm{~km}$ of travel.

Some of this canals reached 147 and $124 \mathrm{~km}$, which corroborate the figures of one hundred miles that Pliny mentions. This last canal made an important transfer of water from the Duero Basin to the Sil Basin. The supply structure reveals the existence of different phases of work in the gold deposit and a very important detail: the operation was interrupted due to exhaustion. The magnitude of this engineering work, essential for the existence of Las Médulas themselves, cannot go unnoticed, and undoubtedly deserves the homonymous recognition that the object for which it was built has already received.

Key words: Roman canals; Roman engineering; Las Médulas; Roman gold mining.

RESUMO: A declaração em 1997 da exploração romana de ouro de Las Médulas como Patrimônio da Humanidade foi um reconhecimento merecido da maior exploração de mineração do mundo antigo. No entanto, essa afirmação ignorou a totalidade deste magnífico trabalho de engenharia, concentrando-se apenas no local único dos picos vermelhos, resíduos dos trabalhos de extração. Desse modo, ficaram de fora os canais de abastecimento de água, essenciais para o colapso da 
ROBERTO MATÍAS RODRÍGUEZ

LOS CANALES DE LAS MÉDULAS (LEÓN-ESPAÑA): RAZONES PARA SU INCLUSIÓN EN EL PATRIMONIO...

montanha, um sistema que o naturalista romano Plínio chama "arrugia», e a recuperação de ouro nos canais de lavagem.

Naquela época, parece que os canais eram considerados um trabalho menor e eram pouco documentados, com a absoluta falta de topografia adequada, apesar de serem amplamente conhecidos pelos nativos da região. Somente em 2004 foi publicada a primeira cartografia detalhada, que agora mostra a surpreendente figura de $600 \mathrm{~km}$ de canais, expandida sucessivamente com novas pesquisas e descobertas em 2008 e 2017, para as quais os $700 \mathrm{~km}$ de passeio.

Para as Medulas, chegaram alguns canais de 147 e $124 \mathrm{~km}$, que corroboram os números de cem milhas que Plínio menciona. Este último canal fez uma importante transferência de águas da Bacia do Douro para a Bacia do Sil. A estrutura de suprimentos revela a existência de diferentes fases do trabalho no depósito de ouro e um detalhe muito importante: a operação foi interrompida por exaustão. A magnitude deste trabalho de engenharia, essencial para a existência das próprias Medulas, não pode passar despercebida e, sem dúvida, merece o reconhecimento homônimo de que o objeto para o qual foi construído já recebeu.

Palavras chave: canais romanos; engenharia romana; Las Médulas; mineração romana de ouro.

\section{INTRODUCCIÓN}

Acercarse a Las Médulas es contemplar la mayor obra de la ingeniería minera de la antigüedad, cuya magnitud no llegó a ser superada hasta casi 20 siglos más tarde, gracias a la introducción de la máquina de vapor como fuerza de trabajo principal. Asomarse a contemplar estos singulares picachos rojos desde el Mirador de Orellán sobrecoge el ánimo cuando en un ejercicio de imaginación, a los pies de este formidable precipicio, tomamos conciencia de que todo lo que contemplan nuestros ojos, cientos de millones de metros cúbicos de sedimentos auríferos, fue derribado, vaciado y procesado para la recuperación del oro, hace ya 2000 años (Fig. 1). Y todo ello, simplemente, mediante el empleo de herramientas básicas y... agua!

La mina de oro romana de Las Médulas ya formaba parte del Catálogo Monumental de España desde principios del siglo XX (Gómez-Moreno, 1925-26) y fue incluida en el Catálogo de Monumentos Históricos Artísticos españoles en 1931. En 1996 recibe el reconocimiento de la Junta de Castilla y León como Bien de Interés Cultural (BIC). Un año más tarde, en diciembre de 1997 el paraje de Las Médulas fue declarado Patrimonio de la Humanidad por la UNESCO en base a que la zona de explotación aurífera de Las Médulas es un ejemplo de excepción de una técnica innovadora romana, en la que todos los elementos que componen el paisaje antiguo, tanto industriales como domésticos, han sobrevivido de forma excepcional, calificando el paraje como una importante obra destacada de 
la creatividad humana. Asimismo, la declaración de la UNESCO destaca el valor de Las Médulas como una evidencia única, o al menos excepcional, de un tipo de trabajo minero y de una explotación tecnológica y científica de la naturaleza que fue llevada a cabo por una civilización extinguida.

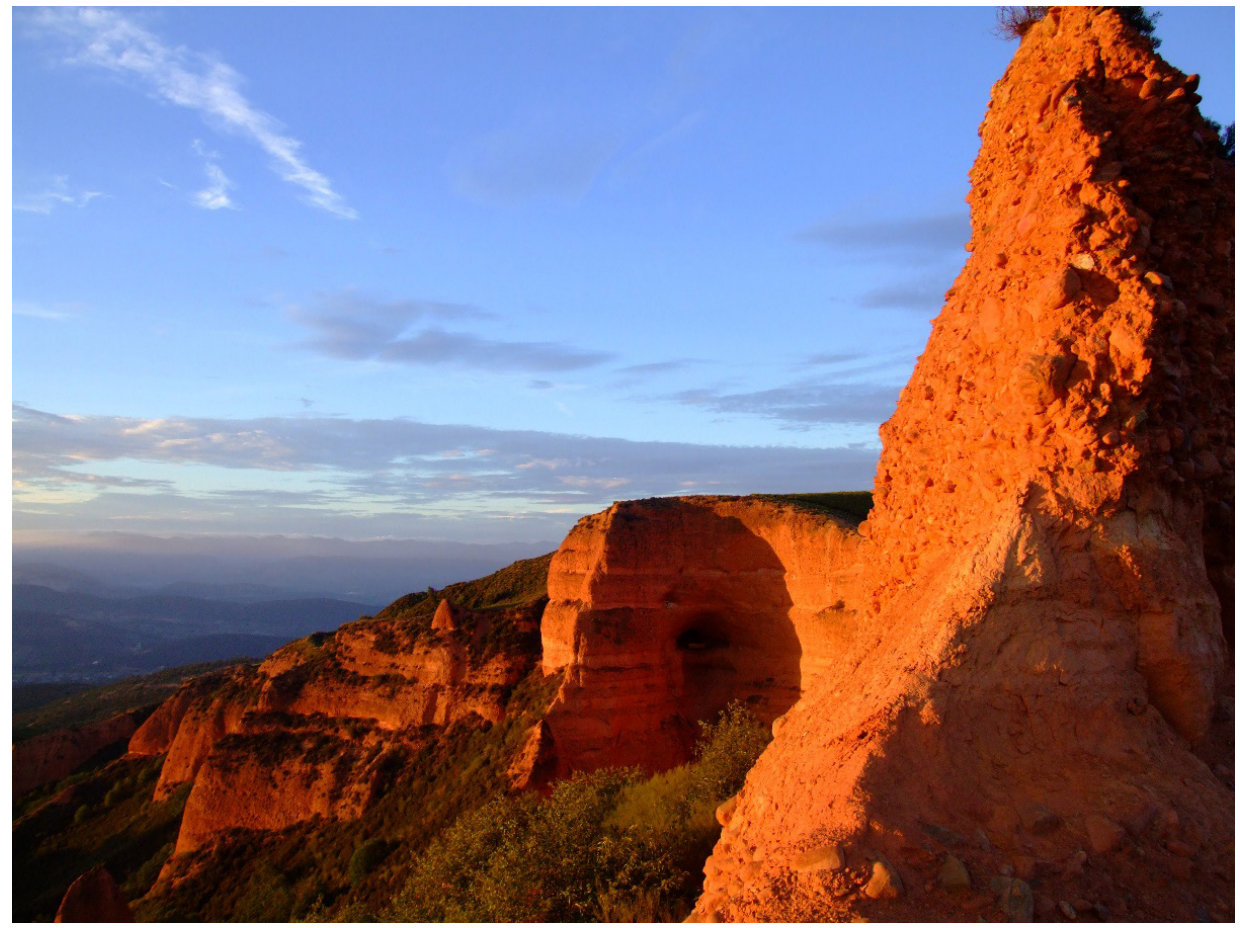

Figura n. ${ }^{\circ}$ 1: Las Médulas vistas desde el Mirador de Orellán.. Foto: R. Matías.

La declaración realizada por la UNESCO se centra únicamente en el paraje donde se registran las espectaculares evidencias de la actividad minera romana. Sin embargo, Las Médulas es una realidad tangible sobre el terreno en una superficie que se irradia hasta casi mil kilómetros cuadrados, sobre los que se extiende una de las mayores redes de suministro hidráulico $(700 \mathrm{~km})$ construida en el inicio de nuestra era, que rivaliza en magnitud con el abastecimiento de la propia ciudad de Roma (Fig. 2). Los ingenieros romanos llevaron el agua necesaria para los trabajos de Las Médulas mediante canales abiertos desde una distancia que supera en varios casos el centenar de kilómetros. Para ello tuvieron que enfrentarse a enormes problemas de planificación y diseño, que llegaron a resolver con éxito. Sorprende todavía actualmente la capacidad desplegada por nuestros antepasados 
ROBERTO MATÍAS RODRÍGUEZ

LOS CANALES DE LAS MÉDULAS (LEÓN-ESPAÑA): RAZONES PARA SU INCLUSIÓN EN EL PATRIMONIO...

para conseguir disponer de grandes cantidades de agua en esta inmensa explotación minera.

Complementaria a la declaración de Patrimonio de la Humanidad, esta zona se amplía geográficamente en 1998 a un conjunto territorial más extenso, transformando el Bien de Interés Cultural de Las Médulas como Zona Arqueológica de Las Médulas (ZAM), modificada y ampliada posteriormente en 2007 (Decreto 101/1998 de 11 de mayo. BOCYL de 2 de junio de 1998. Acuerdo 200/2007 de 26 de julio, de la Junta de Castilla y León. BOCyL n. ${ }^{\circ} 149$ de 1 de agosto de 2007; BOE n. ${ }^{\circ} 217$ de 10 de septiembre de 2007). A esta figura legal hay que añadir la otorgación de la de Monumento Natural en 2002.

Por acuerdo de 23 de diciembre de 2010 del Consejo de Gobierno de la Consejería de Cultura de la Junta de Castilla y León se declara a Las Médulas como Espacio Cultural (ECM), por sus especiales valores históricos y naturales. Se desarrolla entonces un Plan de Adecuación y Usos (PAU) que deberá servir para hacer un diagnóstico y una previsión de su evolución, que establecerá las normas y directrices generales para gestionar el Espacio Cultural y lograr su mejor conservación. En este plan se incluyen ya los canales de Las Médulas como Zona de Afección 2 "La red hidráulica", no sin errores significativos en su distribución geográfica y concepto. En el PAU se define como zona de afección la red de canales, en cuanto elemento inseparable de la zona minera incluida en el ECM. Se trata de una zona extensa y dispersa a lo largo de la comarca de La Cabrera y de los Montes Aquilianos.

Así las cosas, nos encontramos con una declaración de la UNESCO restringida únicamente y de forma muy estricta a los trabajos mineros de Las Médulas, donde su red hidráulica no ha tenido ninguna cabida hasta la tímida clasificación como Zona de Afección 2, en el PAU, tras la definición del Espacio Cultural Médulas. En las siguientes páginas tenemos como objetivo desgranar y poner de relieve la importancia y singularidad de los canales de Las Médulas, inseparablemente unidos a la explotación para la que fueron diseñados, pero relegados al olvido en el Patrimonio de la Humanidad.

\section{LA MINA DE ORO ROMANA DE LAS MÉDULAS Y SU CONTEXTO}

La importante riqueza aurífera de la zona noroeste de la Península Ibérica ya era bien conocida en estos terrenos por sus habitantes locales, como lo atestiguan los numerosos y delicados objetos de orfebrería prerromana hallados en las excavaciones arqueológicas (Oro en la España Prerromana, 1989; Perea y SánchezPalencia, 1995), aunque la explotación parece ser que se limitaba al lavado artesanal de las arenas auríferas de los cauces fluviales, habida cuenta de la ausencia de restos significativos de otros trabajos. 
Esta circunstancia es corroborada por los textos antiguos, según nos relata Estrabón citando a Posidonio de Apamea, quien al parecer llegaría a visitar las costas del noroeste peninsular entre los siglos II y I a. C. (Estrabón, Geographica, III, 2,9):

«... Entre los ártabros, que son los últimos de Lusitanita hacia el noroeste, se dice que la tierra se cubre de pepitas de plata, estaño y oro blanco, puesto que está mezclado con plata, y que esta tierra la arrastrarían los ríos. Las mujeres excavándola con un sacho o azada la lavan en tamices trenzadas sobre cuencos".

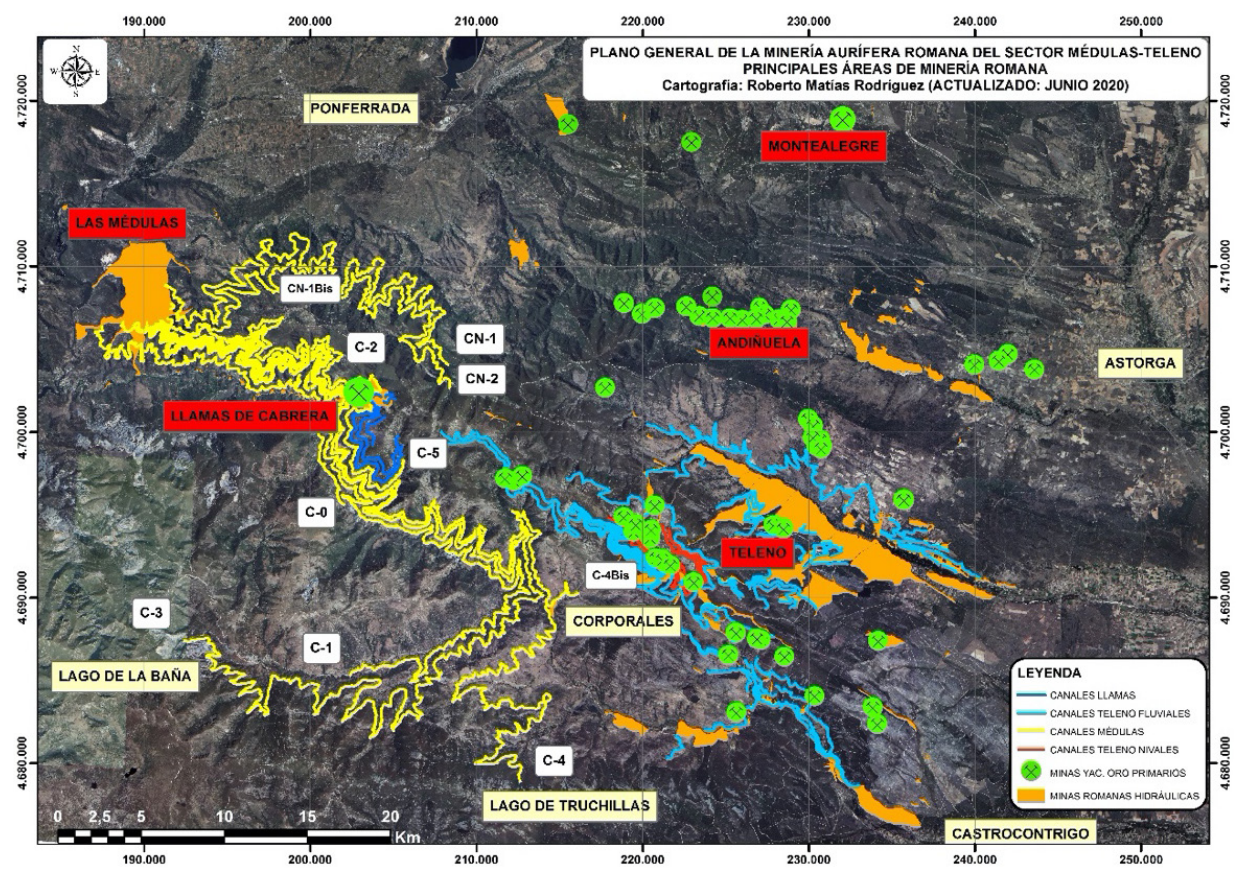

Figura n. ${ }^{\circ}$ 2. Mapa de los canales de Las Médulas y la minería aurífera romana del entorno. Ortoimagen PNOA 2017 cedida por el Instituto Geográfico Nacional (IGN). Datos gráficos: R. Matías.

A comienzos de nuestra era la conquista de los territorios del Noroeste Hispano estaba dentro de los objetivos prioritarios del Imperio Romano, como lo demuestra el amplio despliegue de medios humanos y materiales realizado por Roma para controlar la zona. Tras el largo episodio conocido como Guerras Cántabras (29-19 a. C). culmina la conquista del territorio (Floro, II, 33. 46-60):

...Para Augusto este fue el final de sus quehaceres bélicos y también el fin de la rebelión de Hispania. A partir de entonces fueron fieles y tuvieron una paz duradera, 
ROBERTO MATÍAS RODRÍGUEZ

LOS CANALES DE LAS MÉDULAS (LEÓN-ESPAÑA): RAZONES PARA SU INCLUSIÓN EN EL PATRIMONIO...

no sólo por su ingenio bien dispuesto para las artes propicias de una situación de paz, sino también por el buen entendimiento de César quien recelando de la buena fe de quienes se escondían en los montes, les mandó habitar el campamento suyo que estaba en la zona llana y trabajar la tierra; allí había un consejo del pueblo y aquel campamento era considerado como auténtica capital. Las características de la región favorecían la realización; en efecto, por los alrededores del lugar había oro, malaquita, minio y también abundaban otros productos. Así pues, mandó que se explotase el suelo. Con ello los Astures, excavando la tierra esforzadamente, empezaron a darse cuenta de sus recursos y riquezas, aunque en principio tratan de adquirir todo esto para otros.

La minería del oro se convirtió entonces en la actividad económica principal de un área de más de $90.000 \mathrm{~km}^{2}$ y se pusieron en explotación cientos de yacimientos auríferos, de diversos tipos y tamaños (Domergue, 1987; 2008; Martins, 2008; Perea y Sánchez-Palencia, 1995; Matías, 2014). La exhaustividad de los prospectores romanos fue tal, que al día de hoy no se ha conocido todavía ningún yacimiento de oro que no hubiera sido trabajado ya con anterioridad en época romana, y seguimos todavía encontrando nuevas evidencias de minería aurífera romana (Matías, 2008; 2012; 2017A; Matías et al., 2014; Matías y González-Nistal, 2014; 2014A). Hasta tal punto llegó el grado de explotación minera de estos yacimientos con la tecnología romana que, a pesar de los importantes avances técnicos realizados en la minería y metalurgia del oro en los siglos XIX-XX, y tras numerosos intentos de explotación tanto en León, Portugal, Galicia o Asturias, no ha habido apenas posibilidades de su aprovechamiento.

De los diversos métodos de trabajo desarrollados por los ingenieros romanos para la explotación particular de los yacimientos de oro destacan las técnicas de minería hidráulica en sus diferentes modalidades (Domergue, 1972-74; 2008; 2012). Todas ellas cuentan con un denominador común: el abastecimiento de agua. La minería hidráulica romana no dejó sólo los grandes vaciados que la caracterizan y las enormes acumulaciones de estériles, del orden de millones de metros cúbicos en algunos casos, sino que los canales de abastecimiento constituyen al día de hoy una valiosa muestra de la ingeniería romana (Matías, 2019), todavía insuficientemente valorada. Tan sólo en la mitad occidental de la provincia de León se constata la existencia de más de $1.300 \mathrm{~km}$ de canales cartografiados actualmente en las minas de oro romanas de Las Médulas (Matías, 2008C; 2017), Teleno (Matías, 2006B; Matías y Llamas, 2017), Llamas de Cabrera (Matías, 2008), Villablino (Matías, 2012), Omañas (González y Matías, 2013; Matías y Llamas, 2020), Ancares (Matías, 2020) y otras minas pendientes de publicación. 


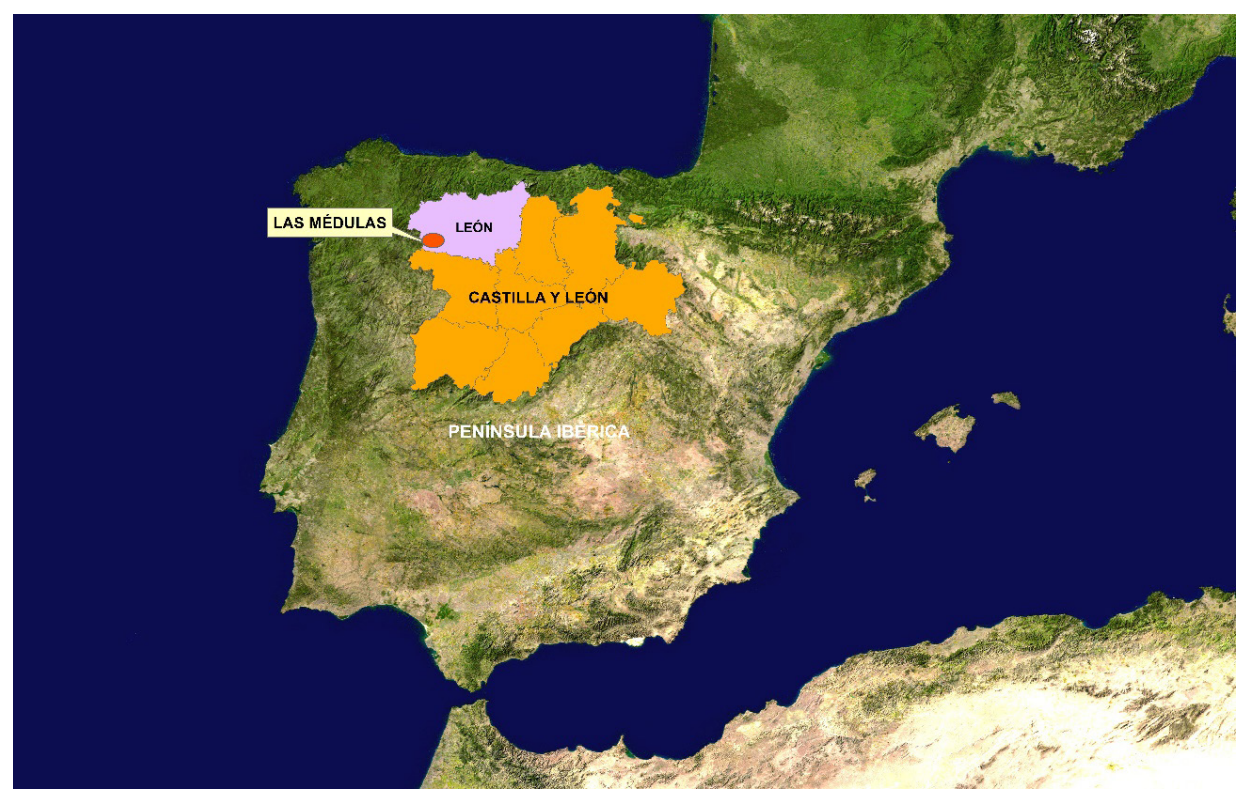

Figura n. ${ }^{\circ}$ 3: Localización de Las Médulas en la Península Ibérica. Ortoimagen LANDSAT, cedida por el IGN.

A lo largo de los tiempos ha destacado siempre entre todas las explotaciones de oro romanas la mina de Las Médulas, situada en el oeste de la provincia de León, a caballo entre las comarcas del Bierzo y La Cabrera, en su parte más occidental (Fig. 3). De hecho, una proporción importante del escueto testimonio sobre la minería de oro romana del naturalista y geógrafo Plinio El Viejo que se recoge en su Historia Natural (PlinNat. 33, 66-78), escrita en la segunda mitad del siglo I, es una referencia clara sobre el modo de explotación minera de este singular yacimiento aurífero (traducción de Pérez y Matías, 2008):

70. El tercer procedimiento superaría los trabajos de los Gigantes. Por medio de galerías, que lleva mucho tiempo hacerlas, se perforan los montes a la luz de las lucernas; estas son la medida de los turnos de trabajo, y durante muchos meses no se atisba la finalización de esta fase. A este tipo de explotación lo llaman arrugias. $\mathrm{Y}$ de repente se forman grietas que provocan derrumbes aplastando a los obreros, de modo que parece ya menos temerario buscar perlas y múrices en el fondo del mar. ¡Hasta tal punto más peligrosa hemos convertido la tierra!. Por esta razón se dejan numerosos arcos para sostener la montaña.

72 ... Acabado el trabajo, abaten los soportes de los arcos comenzando por el último. De esto un derrumbe da la señal y un vigilante que está solo en lo alto de dicha montaña lo percibe. 
73. Este, con gritos y señas, manda evacuar los trabajos y, al mismo tiempo, él baja a toda prisa. La montaña cae desmenuzada por sí misma con un prolongado fragor, tal que la mente humana no es capaz de concebirlo, a la vez que con un golpe de aire increíble. (sc. Los mineros) contemplan victoriosos el derrumbamiento de la naturaleza. Sin embargo, no tienen oro todavía, de la misma manera que no supieron que lo hubiese mientras socavaban, pues la esperanza de encontrar lo que ansiaban era motivo suficiente para afrontar tan grandes peligros y costes.

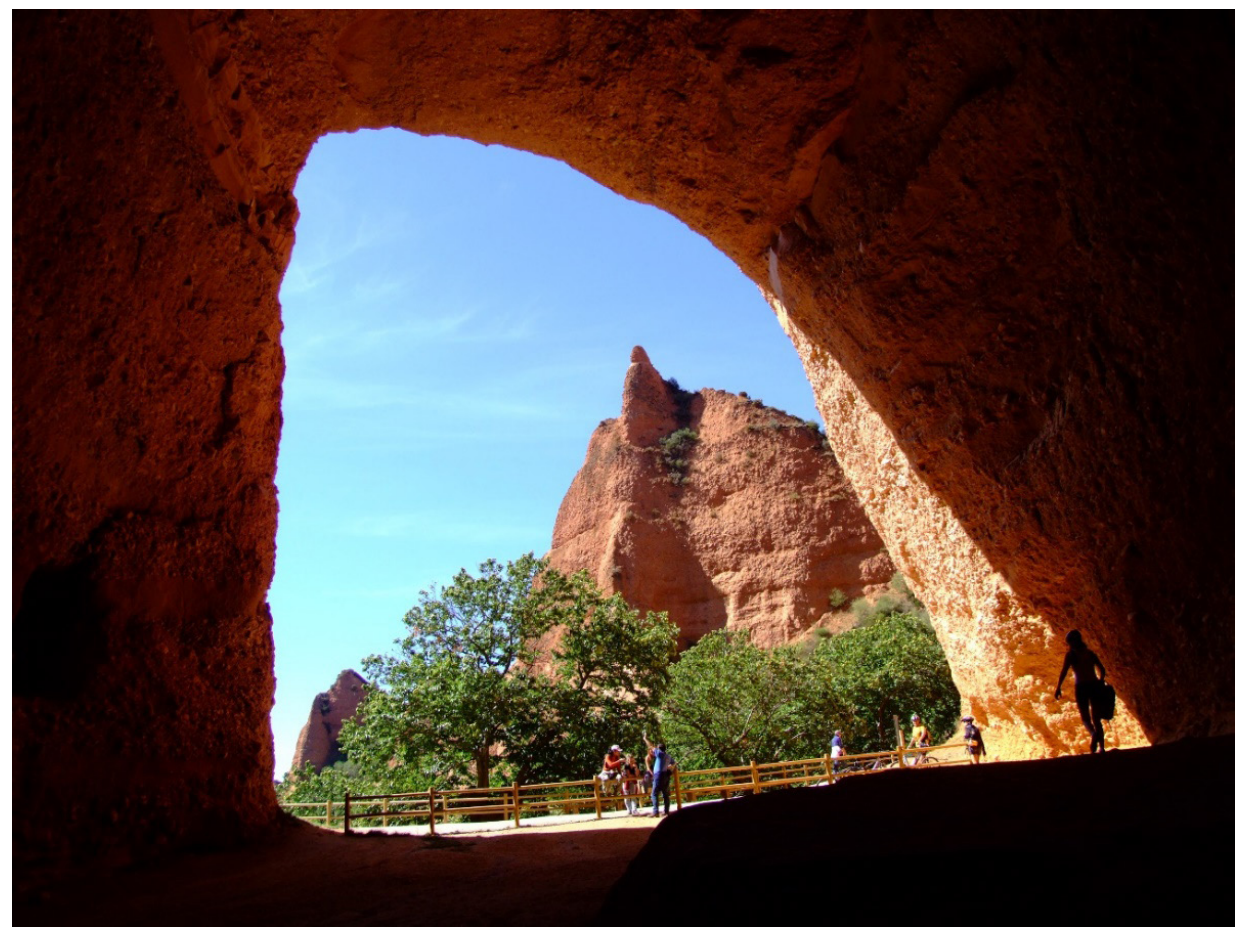

Figura n. ${ }^{\circ}$ 4: La Cuevona. Sector abandonado en fase de derrumbe que ha permanecido en pie. Foto: R. Matías.

La tecnología minera aplicada a Las Médulas es ciertamente singular, ya que sólo se conocen en el Noroeste Ibérico otros dos casos donde se ha aplicado la técnica de arrugia, consistente en la utilización de galerías y agua para abatir acumulaciones de sedimentos auríferos de gran espesor (Fig. 4). Estas minas están situadas una en la provincia de León (La Leitosa), al N de Las Médulas, y la otra en la provincia de Orense (As Borreas de Caldesinhos), al SO. Si damos a Las Médulas una calificación de 10, por ser la de mayor envergadura, La Leitosa tendría un 4 y As Borreas un 3, lo que nos puede dar una idea de la magnitud de los trabajos realizados en Las Médulas. 
ROBERTO MATÍAS RODRÍGUEZ

LOS CANALES DE LAS MÉDULAS (LEÓN-ESPAÑA): RAZONES PARA SU INCLUSIÓN EN EL PATRIMONIO..

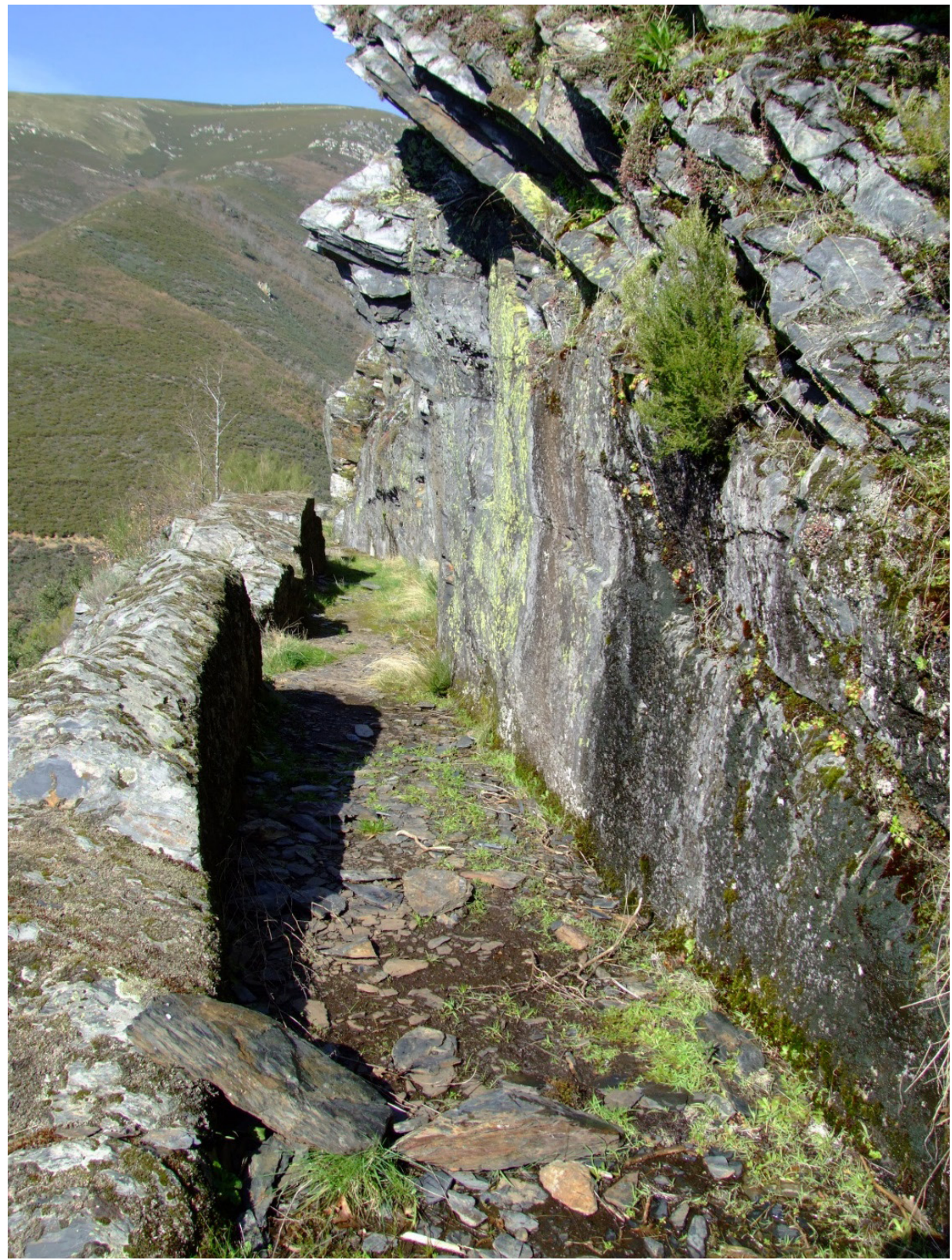

Figura n. ${ }^{\circ}$ 5: Corte en la roca del Canal C-1 en Llamas de Cabrera. Foto: R. Matías. 
ROBERTO MATÍAS RODRÍGUEZ

LOS CANALES DE LAS MÉDULAS (LEÓN-ESPAÑA): RAZONES PARA SU INCLUSIÓN EN EL PATRIMONIO...

\section{LOS CANALES DE LAS MÉDULAS}

La explotación a gran escala del yacimiento aurífero de Las Médulas no hubiera sido posible sin el suministro adecuado y continuo de grandes cantidades de agua que permitiesen convertir la montaña en una masa fluida de lodo, procesarlo en los canales de lavado para recuperar el oro y evacuar a continuación los cientos de millones de metros cúbicos de estériles. La primera valoración sobre la enorme magnitud de la obra de abastecimiento realizada para la explotación de Las Médulas ha quedado muy bien reflejada en la obra de Plinio:

74. Hay otro trabajo similar o incluso de mayor coste: a la vez condujeron desde las cimas de las montañas, generalmente desde una distancia de cien millas, corrientes de agua para lavar este derrubio. Se llaman corrugos, proveniente de conrivatio, a mi parecer. También aquí los trabajos son muy diversos: conviene que la nivelación esté en pendiente para que (sc. el agua) corra apresuradamente mejor que fluya; así pues se trae de zonas muy altas. Las gargantas y crestas se unen con canales apoyados sobre cimientos. En otros lugares se cortan las rocas inaccesibles y se las dispone para proporcionar asiento a troncos colocados en huecos.

75. Quienes hacen los cortes están colgados con cuerdas, de modo que a quien observa de lejos ni siquiera le parecen animales salvajes, sino pájaros. Suspendidos en el aire, nivelan y trazan las líneas del recorrido en su mayor parte, y se canalizan las aguas por donde no hay lugar para las pisadas del hombre. Surge una dificultad en el proceso de lavado, si la corriente de agua produce barro; este tipo de terreno se llama urio. En consecuencia, la conducen por rocas y piedras y evitan el urio. En la parte más alta desde la que se vierte el agua, en las crestas de los montes, se cavan estanques de doscientos pies por cada lado y diez de profundidad. En ellos se dejan cinco desaguaderos de unos tres pies cuadrados a fin de que, lleno el estanque, una vez retirados los cierres el torrente irrumpa con tanta fuerza que arrastre las rocas.

Tras la paralización de los trabajos mineros en Las Médulas al agotar las posibilidades de producción de este yacimiento, los romanos continúan la extracción de oro en otras zonas próximas, hasta el cese total de la actividad extractiva en la zona al alcanzar el límite de explotación de los yacimientos por causas tecnológicas en los primarios y por agotamiento en los secundarios (Matías, 2008b). Los canales, perdida su finalidad, se integran en el territorio como magníficas vías de comunicación y una buena parte de ellos se rehabilitan paulatinamente para servir de acceso entre poblaciones o hacia las zonas de producción agrícola o forestal. Es importante reseñar en este punto que la mayoría de las localidades actuales que se encuentran intercaladas en el trazado de la red hidráulica de Las Médulas tienen un posible origen relacionado con los asentamientos encargados de su construcción y mantenimiento.

De un modo u otro los canales (Fig. 5) han vertebrado secularmente la geografía de su territorio de influencia, permaneciendo hasta la fecha fuertemente arraigados en la tradición oral. Sin embargo, la escasez de referencias en las fuentes escritas es notable. Destaca a principios del siglo XIX la primera descripción desde el terreno sobre el sistema de explotación hidráulico de Las Médulas, que 
ROBERTO MATÍAS RODRÍGUEZ

LOS CANALES DE LAS MÉDULAS (LEÓN-ESPAÑA): RAZONES PARA SU INCLUSIÓN EN EL PATRIMONIO...

la realiza el Teniente Coronel de Artillería Juan Manuel Munárriz en 1807, después de varios años de estancia en el Bierzo con objeto de evaluar el proyecto de la instalación de una fábrica de pólvora en Villafranca del Bierzo (Munárriz, 1808):

En la cima de todos estos montecillos se descubren aún señales de un depósito o balsa de agua más o menos grande al que van a parar una, dos o más acequias, que se dirigen al río más próximo, costeando montañas altas y escarpadas con galería y otras obras, que admiran por su mucho trabajo y buena dirección, teniendo dichas acequias tres, cuatro y hasta ocho o diez leguas de extensión. A bastante trecho del pie de los mismos montes no se ven más que montones enormes de piedra gruesa con un canal o barranco en medio que va a desaguar siempre en algún río o arroyo, en el que formaban balsas más pequeñas que en las de arriba. Los que removían el terreno separaban a brazo la piedra gruesa que el agua no podía arrastrar. Sobre la tierra ya removida dejaban caer con ímpetu el agua de las balsas que había en la altura....Hay grandes excavaciones, cuevas, pozos y galerías que se comunican entre si, y otras están cegadas por las inclemencias del tiempo, cuyas obras ejecutaron tanto para extraer la tierra que querían beneficiar como para dar salida a las aguas que trajeran del río Cabrera y de los arroyos de Corporales, y de unas fuentes inmediatas al origen del Oza, de ocho y diez leguas de distancia, por medio de siete canales o acequias hechas una encima de otra, al parecer en distintas épocas, costeando altas y peñascosas montañas, atravesándolas en parte por galerías, de lo que subsisten aún hoy día señales en los mismos montes (Fig. 6).

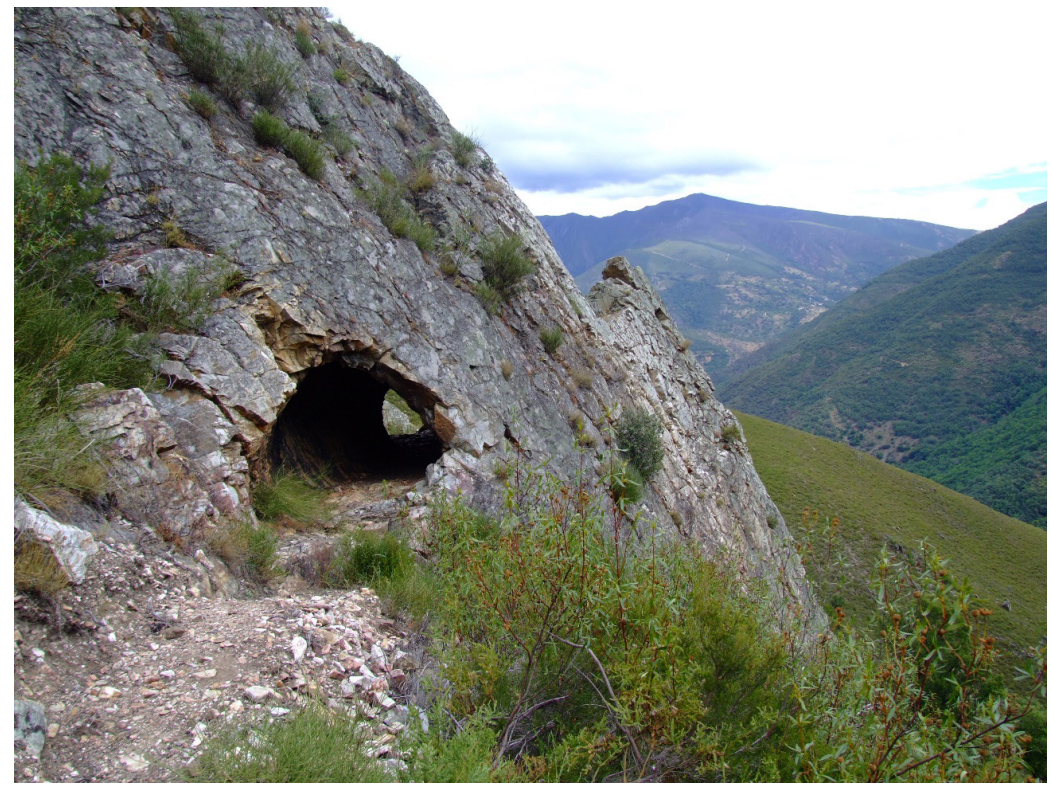

Figura n. ${ }^{\circ}$ 6: Túnel del canal C-1 en las inmediaciones de Pombriego-Santalavilla. Foto: R. Matías. 
ROBERTO MATÍAS RODRÍGUEZ

LOS CANALES DE LAS MÉDULAS (LEÓN-ESPAÑA): RAZONES PARA SU INCLUSIÓN EN EL PATRIMONIO...

Las propias Médulas y sus canales ocupan un lugar importante en la bibliografía del escritor berciano del siglo XIX, Enrique Gil y Carrasco, principalmente en su obra Bosquejo de un Viaje a una Provincia del Interior (Gil y Carrasco, 1843):

En pocas partes ha dejado el pueblo rey un testimonio más vivo y elocuente del atrevido espíritu, en cuyas alas volaba su pensamiento. Fecundas eran, sin duda, las entrañas de aquellos cerros, purísimo el oro que les brindaba, sano y templado el país que los cercaba y sereno el cielo que los cubría; pero la naturaleza se había empeñado en poner a su codicia un valladar insuperable, si alguno hubiera para ella. En el estado de las ciencias naturales, en aquel entonces, la mineralogía era tal vez la que más se resentía del común atraso. Plinio nos describe prolijamente en el lugar ya citado el método de que en su tiempo se usaba para obtener el oro; método verdaderamente primitivo, pues tenía por base y principio el mismo lavado, que si no en forma, por lo menos en la esencia, emplean aún hoy en el día las muchas mujeres que en el valle de Valdeorras ganan su vida sacando oro de las entrañas de las arenas del Sil.

Pero, ¿dónde buscar las corrientes de agua necesarias para semejante procedimiento en un paraje alto y sin más raudales que los diminutos de las fuentes de los valles?... ¿Pondrían los ojos y la atención en el Oza, que riega el hondísimo Valdueza, o en el río de Cabrera, que poco más abajo desemboca en el Sil, ambos divididos por escabrosas cordilleras y a un espantoso desnivel del lugar en cuestión?. Pero este parecería un loco intento al que apenas podría dar cima el poder humano. Sin duda, los romanos no hubieron de calcular de la misma manera, antes remontando el curso de estos ríos, registrando las cuevas y proyecciones del terreno y midiendo exactamente las alturas, hallaron que sus aguas podían venir a pulimentar y laborar cuanto mineral sacasen del seno de Las Médulas...

...Si alguno de los lectores ha cruzado estas cordilleras y visto su naturaleza peñascosa y ruda, las tajadas quiebras y profundos valles que las surcan, conocerá la penalidad infinita con que debieron abrirse los canales que, colgados en escarpadísimas pendientes, todavía hoy nos suspenden y hielan de pasmo. Sujetos a seguir en su dirección todas las inflexiones y desigualdades de los cerros, sus rodeos son mayores de lo que a primera vista parece y una distancia que por el aire apenas llegaría a dos leguas, tal vez pase de ocho o diez en la forma actual... Dividíanse ambas líneas en varios ramales, sin duda con el objeto de aprovechar cuantos manantiales encontrasen en su tránsito. Cuéntase en Cabrera, según nos han informado, hasta siete cauces escalonados en la vertiente de las montañas que mira al norte y, desde un punto que domina el pueblo de Orellán, se divisan algunos todavía. La otra línea, repartida en menos conductos por llevar también algo menor cantidad de aguas, arrancaba de las alturas que dan cima al Oza, pasaba por encima del monasterio de San Pedro de Montes, torcía más adelante el paso por el valle de Villanueva y, después de seguir todavía algunos recodos, iba a desembocar en los lavaderos de las minas. Agradable debía de ser la vista de todos estos raudales que como otras tantas cintas de plata culebreaban perdiéndose y volviendo a aparecer en los senos de aquellas montañas tan ásperas, solemnes y silenciosas. 
ROBERTO MATÍAS RODRÍGUEZ

LOS CANALES DE LAS MÉDULAS (LEÓN-ESPAÑA): RAZONES PARA SU INCLUSIÓN EN EL PATRIMONIO...

A mediados del siglo XIX, el eminente ingeniero de minas español Casiano de Prado, figura de reconocido prestigio en toda Europa, visita la zona de Cabrera y, sobrecogido por la magnitud de los trabajos de Las Médulas, las describe en los siguientes términos (Prado, 1862):

Los romanos lavaban las arenas, separando los cantos rodados que se hallaban entre ellas, y llevándolos á distancia conveniente, donde los disponian en montones que llaman murias. El movimento de tierras que efectuaron para estos disfrutes es cosa que sorprende, sobre todo en las Médulas, donde se ven cortes de grande altura y mogotes ó damas, que algunos forman puntas muy agudas. Las aguas que produjeron estos depósitos á pesar de la altura en que se hallan, no podian tener una corriente violenta á juzgar por las lineas horizontales de asiento que en ellos no dejan de percibirse. En estos cortes no se halla ahora oro alguno, pero no debía de suceder lo mismo en la parte escavada, que forma una grande hondonada.

Sobre los canales, Prado nos da esta visión desde su propia perspectiva y recogiendo también la tradición local:

Muchos son los tesoros que allí y en las cercanias sacaron ó esperaban sacar los romanos, pues para lavar las tierras llevaron por las laderas de los montes las aguas del Cabrera y otros rios por medio de cauces abiertos ó construidos con la mayor solidez. En el país dicen que hay siete. Yo he visto tres entre Llamas y Odollo á 30 ó 40 metros de distancia entre si en altura y acaso 100 sobre el rio el más bajo. Allí les llaman carriles, porque esto parecen desde lejos... Se observan restos de estos cauces, segun dicen, desde el mismo nacimiento del Cabrera.

Termina Prado su descripción de la siguiente forma: "Materia es esta que merecia un estudio especial, y que yo no be tenido tiempo de hacern.

Lamentablemente, dicho estudio nunca llegó a hacerse y poco a poco se fue perdiendo en la bibliografía el conocimiento secular, que siempre ha permanecido en la zona. Tras la publicación de Gómez Moreno (1925-26) de su Catálogo Monumental de la Provincia de León se difumina definitivamente el hecho de que los canales remontaban el río Cabrera hasta su nacimiento. Autores como Sáenz y Vélez (1974) tratan el tema de Las Médulas, donde hacen una aproximación a su sistema de abastecimiento, que cifran en $200 \mathrm{~km}$, indicando la absoluta necesidad de medir con precisión las pendientes. Critican la confusión existente sobre los canales, que copian indiscriminadamente a otros, o se hacen caso de "consejas locales» sin ningún fundamento.

El desconocimiento y, hasta cierto punto, desinterés por los canales de abastecimiento de Las Médulas, se mantiene a lo largo de las últimas décadas del siglo XX. Como trabajos en los que se hace mención a los canales es aclaratorio consultar los diferentes enfoques que hacen autores como David Gustavo López (1980; 1996; 2005), Javier Sánchez-Palencia y su equipo de investigación del CSIC (1980; Fernández-Posse y Sánchez-Palencia, 1988; Sánchez-Palencia et al., 1992; Sánchez-Palencia y Pérez, 2000; Pérez, 2001; Sánchez-Palencia y Sastre, 2002; 
ROBERTO MATÍAS RODRÍGUEZ

LOS CANALES DE LAS MÉDULAS (LEÓN-ESPAÑA): RAZONES PARA SU INCLUSIÓN EN EL PATRIMONIO...

Sánchez-Palencia y Sastre, 2015). Sin entrar a fondo en ello, ya que excedería el propósito de este trabajo, el denominador común es la visión superficial y sin datos topográficos, haciendo referencia a la existencia de un elevado número de canales, múltiples ramales y bifurcaciones. Este ambiente queda resumido en la siguiente sentencia: "Es poco menos que imposible reconstruir en la actualidad el trazado completo de los canales que abastecían minas de oro como Las Médulas" (Sánchez-Palencia y Sastre, 2002).

A pesar de este ambiente generalizado de desahucio, el descubrimiento casual en el 2002 del complejo de minería aurífera romana de Llamas de Cabrera sentó las bases metodológicas para iniciar la investigación y cartografía de la red hidráulica de Las Médulas. En el 2004 se presentaron ya los primeros resultados (Matías, 2004; 2004A), ampliados y complementados sucesivamente en los años siguientes (Matías, 2006; 2006A; 2008A; 2008B; 2008C). Incluso, en una reciente publicación se ha continuado ampliando la red hidráulica de Las Médulas gracias al hallazgo de nuevas evidencias de canales (Matías, 2017).

Hoy sabemos ya con mucha precisión que para la explotación de Las Médulas se construyó un impresionante conjunto de casi $700 \mathrm{~km}$ de canales de abastecimiento de agua que se encuentra emplazado en las vertientes norte y sur de los Montes Aquilianos, estribación montañosa que constituye la parte más occidental de la Sierra del Teleno, en cuyo extremo final hacia el oeste se encuentra el yacimiento de Las Médulas. El trazado de los canales se prolonga en dos casos hacia la vertiente norte de la Sierra de La Cabrera (Peña Trevinca) cerca ya del nacimiento del río Cabrera, describiendo un gran arco con objeto de captar sus aguas en el entorno de las localidades de La Baña y Encinedo. Se constata en todo momento la captación preferente y específica del caudal del río Cabrera (Cuenca del Sil), principalmente, a la que le siguen en importancia la del río Eria (Cuenca del Duero) y la captación del río Oza (Cuenca del Sil), esta ya correspondiente a la vertiente norte de los Montes Aquilianos. Algunos arroyos de cierta importancia también fueron objeto de captación por canales de menor recorrido. 
ROBERTO MATÍAS RODRÍGUEZ

LOS CANALES DE LAS MÉDULAS (LEÓN-ESPAÑA): RAZONES PARA SU INCLUSIÓN EN EL PATRIMONIO...

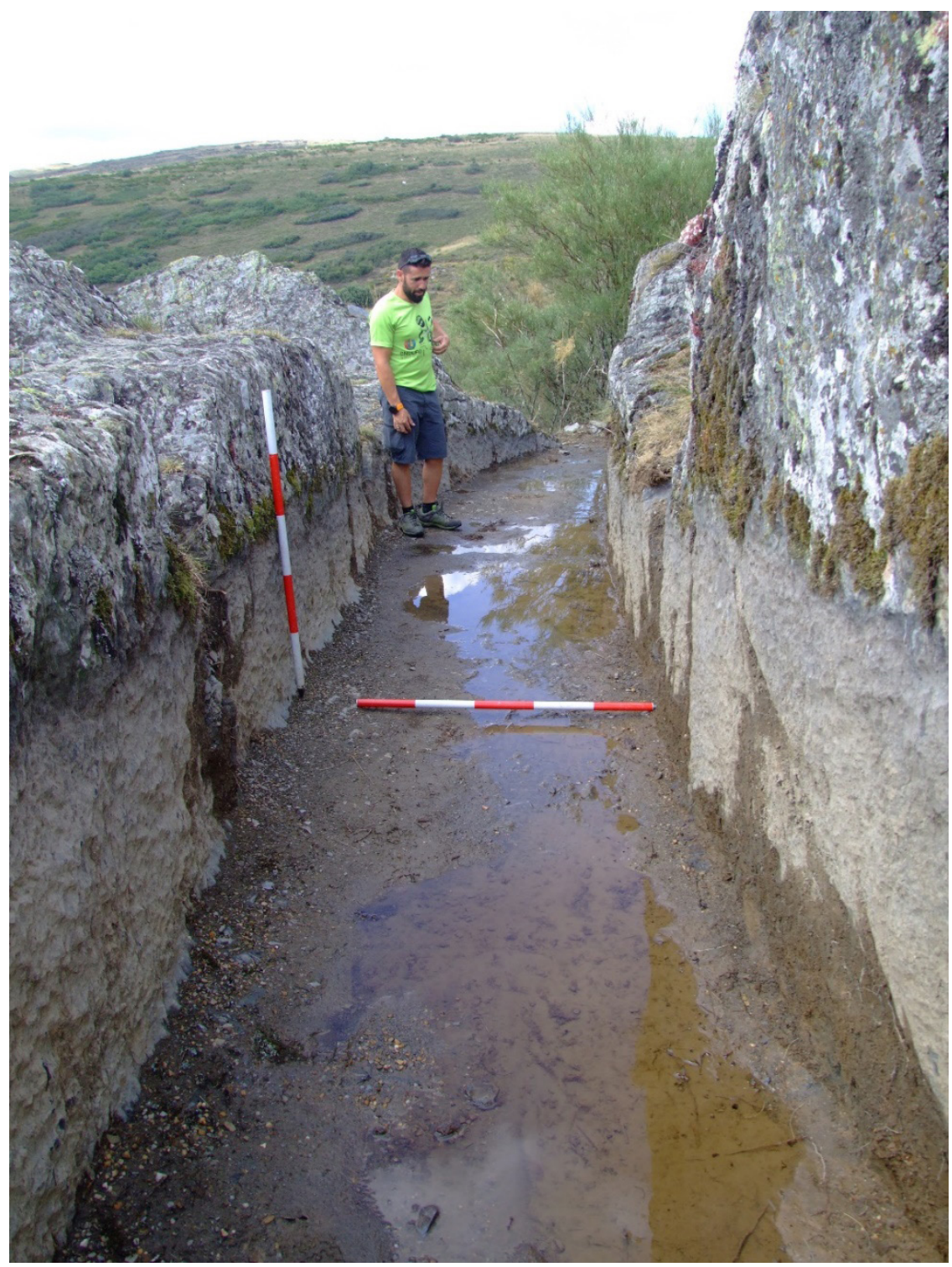

Figura n. ${ }^{\circ}$ : Caja del canal C-4 en el Puerto de Peña Aguda (Corporales).

La red hidráulica construida por los ingenieros romanos para la explotación de Las Médulas presenta la siguiente estructura de abastecimiento y longitudes de trazado, referenciados en orden ascendente: 
ROBERTO MATÍAS RODRÍGUEZ

LOS CANALES DE LAS MÉDULAS (LEÓN-ESPAÑA): RAZONES PARA SU INCLUSIÓN EN EL PATRIMONIO...

3 CANALES en la vertiente norte de los montes Aquilianos (Bierzo-red septentrional).

CN-1 73,37 km (Captación: río Oza en Peñalba de Santiago).

CN-1Bis 20,13 km (Captación: Arroyo de Ferradillo en Villavieja).

CN-2 58,11 km (Captación: río Oza en Peñalba de Santiago).

6 CANALES en la vertiente sur de los montes Aquilianos (Cabrera-red meridional).

C-0 43,03 km (Captación: río Cabrera en Odollo).

C-1 95,60 km (Captación: río Cabrera en Encinedo).

C-2 33,90 km (Captación: Arroyo Valdecorrales).

C-3 148,46 km (Captación: río Cabrera en La Baña).

C-3 a 9,94 km (Subsidiario del C-3 desde el Arroyo de Rozana-Pombriego).

C-3 b 9,50 km (Subsidiario del C-3 desde el Arroyo de Rozana-Pombriego).

C-4 125,56 km (Captación: río Eria en Corporales y Lago de Truchillas).

C-4Bis $\quad 3,66 \mathrm{~km}$ (Ramal de captación del río Eria).

C-5 45,30 km (Captación: Arroyo de la Sierra en Odollo).

TOTAL TRAZADO: 666,56 km*

* (actualización de mediciones sobre cartografía digital a $\mathrm{E}=1: 2.000$. Los datos de mediciones anteriores fueron realizados sobre mapas físicos de $\mathrm{E}=1: 10.000)$.

La red septentrional buscaba la captación del limitado caudal del río Oza en el entorno de Peñalba de Santiago mediante dos canales principales que intervinieron tanto en el comienzo de la explotación (CN-1), suministrando agua a la cota $810 \mathrm{~m}$, como en la etapa final (CN-2), mediante el aporte a la cota máxima de abastecimiento $(978 \mathrm{~m})$, desde la que se realizó la última fase de trabajos en la mina (Matías, 2016). Se ha constatado ahora también la existencia de un tercer canal en la red septentrional denominado $\mathrm{CN}-1 \mathrm{bis}$, de corto recorrido $(19,3 \mathrm{~km})$ que captaba las aguas del Arroyo de Ferradillo en Villavieja efectuando el suministro a la zona central del yacimiento a la cota 880 m (Matías, 2008A).

La red de canales meridional (Cabrera-vertiente sur de los Montes Aquilianos) resulta mucho más extensa y compleja, contando con 6 canales principales que abastecían a Las Médulas desde la cuenca del río Cabrera, teniendo tres de ellos (C-0, C-1 y C-3) su captación directamente en el propio cauce de este caudaloso río. Otro canal (C-4) realizaba un trasvase de cuencas, recogiendo las aguas del río Eria en la localidad de Corporales, de donde sale también un ramal recientemente descubierto de $43 \mathrm{~km}$ que llegaba hasta las inmediaciones del Lago de Truchillas para captar las aguas de su entorno (Matías, 2017). Los dos canales restantes aprovechaban el agua de arroyos tributarios del río Cabrera en Llamas de Cabrera (C-2) y Odollo (C-5). 
ROBERTO MATÍAS RODRÍGUEZ

LOS CANALES DE LAS MÉDULAS (LEÓN-ESPAÑA): RAZONES PARA SU INCLUSIÓN EN EL PATRIMONIO...

\section{III.1. Construcción}

Los canales fueron concebidos como estructuras lineales de conducción de agua de sección rectangular, destinadas a la captación de las principales fuentes de abastecimiento disponibles (ríos) que garantizasen así un suministro continuo y regular de agua en cualquier época del año. Todo indica que los canales han sido realizados partiendo de las cotas de utilización en la mina hacia los puntos de captación de agua. Aunque la vista más espectacular de los canales de Las Médulas es la de los cortes producidos en el terreno cuando se tienen que atravesar farallones rocosos (Fig. 7), la mayor parte del trazado se realizó excavando parcialmente la caja del canal en la ladera de la pendiente y preparando un muro de cierre exterior, firmemente asentado en el terreno mediante sendos escalones, tallados a ser posible en la roca firme. Este muro de cierre sirve a la vez como corredor de servicio para permitir eventuales reparaciones rápidas y un correcto mantenimiento. La situación de la mayoría de los tramos de canal en laderas empinadas los hace muy expuestos a obstrucciones y roturas por deslizamientos del terreno o caída de rocas, troncos, etc.

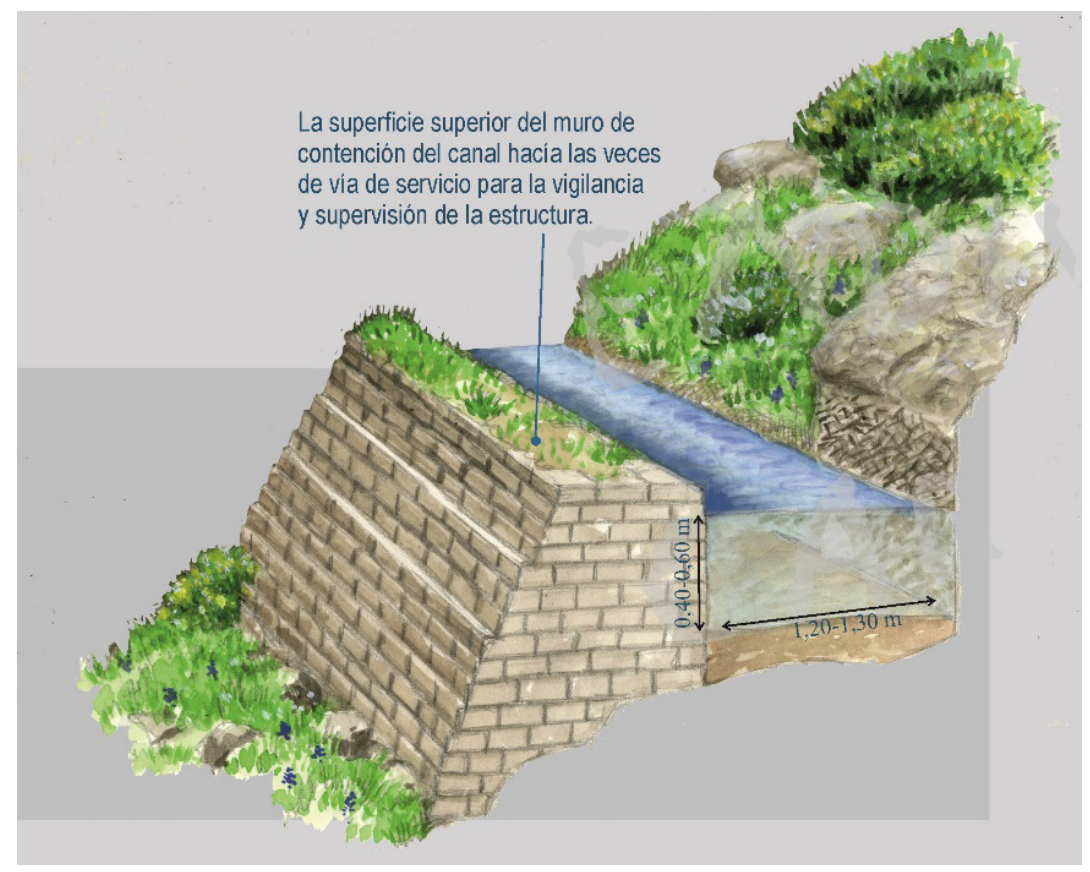

Figura n. ${ }^{\circ}$ 8: Reconstrucción gráfica de la estructura de un canal de Las Médulas. Dibujo: Luis Frechilla. 


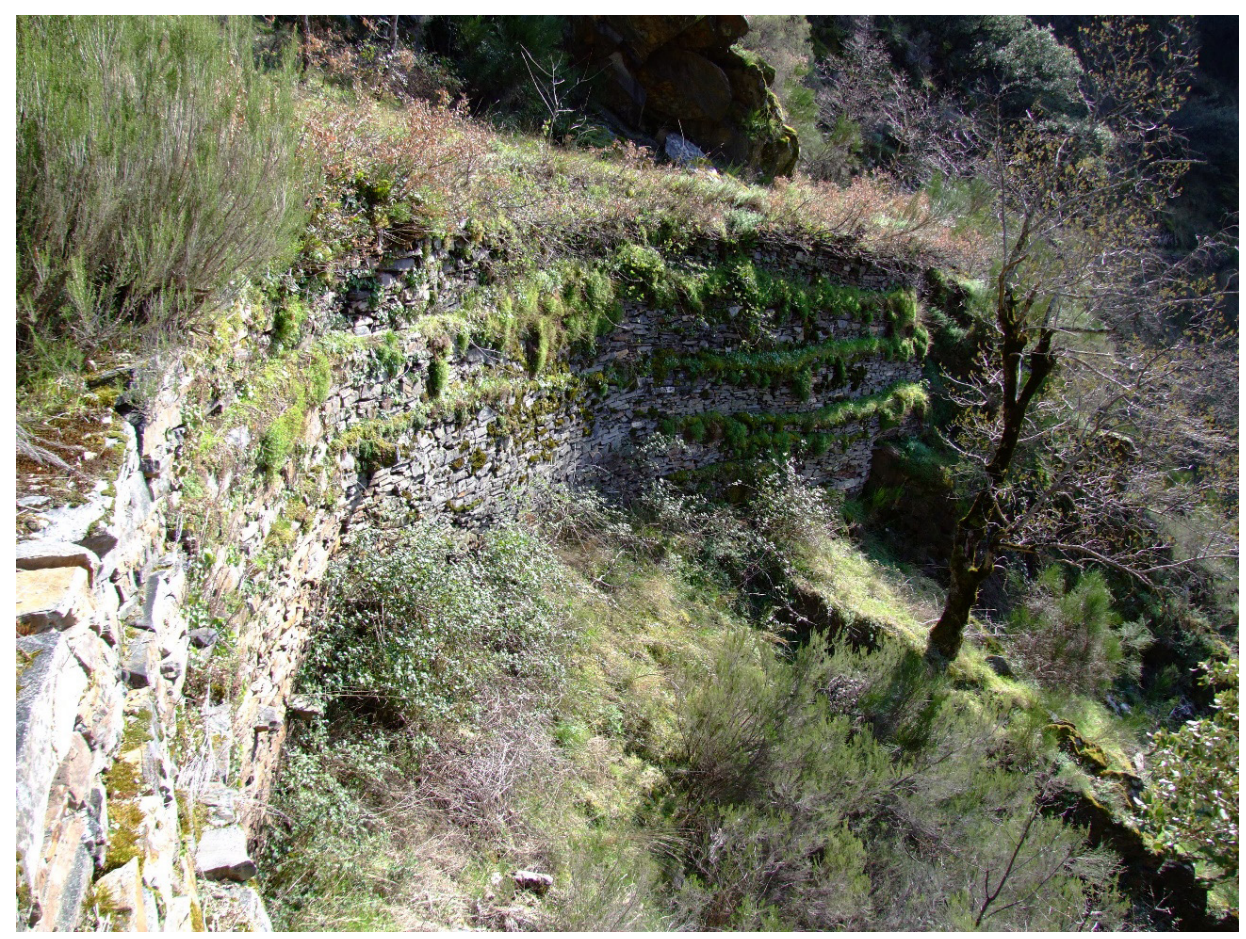

Figura n. ${ }^{\circ} 8$ A: Muro de sostenimiento del canal C-1 en el Valle Lleiroso de Llamas de Cabrera. Foto: R. Matías.

El muro se realizaba en mampostería de piedra en seco, aprovechando en todo momento los diversos materiales del terreno circundante (Figs. 8-8A). En el estado actual de las investigaciones no se han encontrado evidencias de haber utilizado un revestimiento impermeabilizante, si bien se ha constatado en algunos puntos que la cara interior del muro del canal en contacto con el agua tiene las juntas realizadas con tierra como agente de impermeabilización.

A primera vista la construcción de canales de estas características puede parecer una tarea sencilla, pero cuando hablamos de grandes longitudes de trazado y pendientes tan reducidas y precisas, además de un emplazamiento en condiciones topográficas muy adversas, la tarea ya adquiere otros niveles de dificultad. Por las huellas de los picos dejadas en el terreno se aprecia que la excavación de la caja del canal fue realizada en varias fases (hasta tres se han podido constatar) de tal forma que podemos asegurar que hubo un trazado inicial nivelado que precisó de un importante desbroce del terreno (posiblemente realizado mediante el incendio de la masa forestal) sobre el que excavar posteriormente la caja del canal, seguido de una primera fase de nivelación gruesa que precede a una segunda nivelación 
ROBERTO MATÍAS RODRÍGUEZ

LOS CANALES DE LAS MÉDULAS (LEÓN-ESPAÑA): RAZONES PARA SU INCLUSIÓN EN EL PATRIMONIO...

más fina que es la que proporciona al canal su acabado definitivo. Las técnicas topográficas empleadas (Moreno, 2004; 2015) resultaron muy efectivas y sorprenden, al día de hoy, por los resultados conseguidos al enfrentarse a nivelaciones tan precisas.

Sobre el controvertido aspecto de la utilización de troncos ahuecados, traducción literal del texto de Plinio en todas sus versiones (Pérez y Matías, 2008), es posible observar múltiples evidencias en el terreno de los encajes destinados a la colocación de los troncos que permitían la construcción del canal por encima para permitir el paso por algunos lugares escarpados, sin necesidad de realizar una sobreexcavación de la caja. Evidentemente, se trata de pequeños tramos de apenas 2-3 m, realizados para salvar obstáculos puntuales en terrenos muy escarpados. Si el obstáculo es mayor, se optaba ya por una excavación en semitúnel, lo más habitual (Fig. 9), o túnel directamente, aunque con mucha menor frecuencia.

\section{III.2.Capacidad de suministro}

La construcción de los canales de Las Médulas permitió a los ingenieros romanos disponer de grandes cantidades de agua que ya podemos conocer y cuantificar gracias a su reconstrucción topográfica. Los datos de pendiente y geometría de los canales son imprescindibles para esta tarea. Técnicamente se trata de canales rectangulares abiertos en los que el flujo del agua viene determinado básicamente por la sección, pendiente y rugosidad de las paredes (Forchheimer, 1935; King \& Brather, 1962; Liria, 2001).

Por los reconocimientos de campo efectuados, la sección efectiva de un canal de Las Médulas es de 1,20 m de anchura, permitiendo niveles de llenado seguros de 40-60 cm. El estudio moderno de los canales de sección rectangular establece que la sección hidráulica óptima, es decir, la de mayor rendimiento, es aquella que transporta una masa de agua cuyas dimensiones son el doble de ancho que su altura (López, 2001), lo que coincide con lo observado en los canales de Las Médulas $(1,20 \times 0,60 \mathrm{~m})$.

La pendiente media oscila entre el $0,15 \%$ y $0,44 \%$, si bien, los valores habituales se mueven en torno al 0,2\% y $0,3 \%$, es decir, un desnivel de $2-3 \mathrm{~m}$ por kilómetro recorrido, prácticamente imperceptible sobre el terreno. Pendientes superiores comprometerían la integridad del canal al aumentar la velocidad del agua. Un estudio pormenorizado de los valores de la pendiente relacionados con la topografía de cada canal (Matías, 2006; 2008B) muestran sensibles variaciones intencionadas tanto a la hora de salvar obstáculos como farallones de roca o realizar captaciones. También se observa un ligero incremento de la pendiente en los canales de las fases finales de trabajo. La conservación de la máxima profundidad de lámina de agua es un factor fundamental para garantizar la capacidad de suministro de estos canales. La disminución de $10 \mathrm{~cm}$ en una lámina de agua de 0,60 m supone una pérdida del caudal del 22,5\%. 


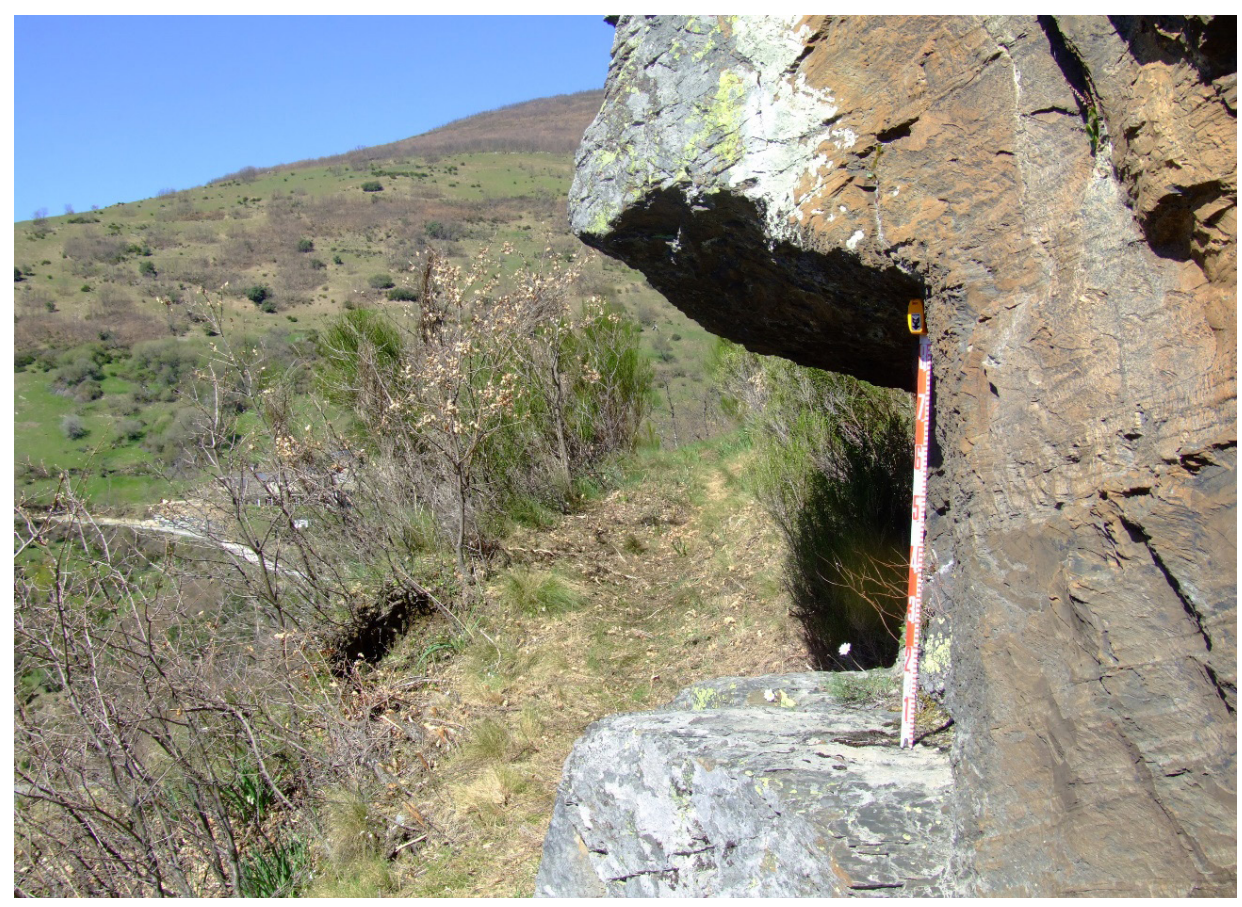

Figura n. ${ }^{\circ}$ 9: Sección en semitúnel del canal C-3 en las inmediaciones del santuario de la Virgen del Valle (Llamas de Cabrera). Foto: R. Matías.

En resumen, teniendo en cuenta la geometría de construcción de los canales, el desarrollo de la explotación de Las Médulas y los diferentes grupos de canales que intervinieron en cada fase, estamos en condiciones de afirmar que el suministro de agua podría haber llegado a alcanzar la impresionante cifra de 50-90 millones de metros cúbicos anuales (Tabla I).

Conociendo la disponibilidad hídrica para la explotación, las fases de trabajo que se pueden deducir del análisis de la red hidráulica y el hecho de que se ha constatado la existencia de importantes evidencias de actividad minera en el complejo de minería aurífera de Llamas de Cabrera, que destruyen por completo la red meridional, nos obliga a un planteamiento diferente de la historia conocida de Las Médulas hasta la fecha, donde queda claro que el yacimiento aurífero fue explotado por los romanos hasta el agotamiento (Fig. 10), en contra de la mayoría de las tesis establecidas hasta ahora en las que se opina que el cese de actividad en Las Médulas fue debido a una crisis del sistema monetario iniciada en el siglo III, debilitándose el valor que había tenido el oro, lo que tuvo como consecuencia la paralización simultánea de toda la minería de este metal en el noroeste hispano (Sánchez-Palencia, 2002). 
ROBERTO MATÍAS RODRÍGUEZ

LOS CANALES DE LAS MÉDULAS (LEÓN-ESPAÑA): RAZONES PARA SU INCLUSIÓN EN EL PATRIMONIO...

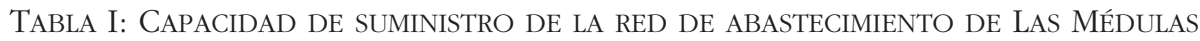
CANALES DE LAS MÉDULAS

\section{CAPACIDAD TÉCNICA TEÓRICA DE SUMINISTRO POR FASES}

(en millones de metros cúbicos por año)

\begin{tabular}{|c|c|c|c|c|c|}
\hline FASES & CANAL & LONGITUD & PENDIENTE media & $\begin{array}{l}\text { CAUDAL } \mathrm{Mm}^{3} / \text { AÑo } \\
0,40 \mathrm{~m} \text { lámina de agua }\end{array}$ & $\begin{array}{l}\text { CAUDAL } \mathrm{Mm}^{3} / \text { AÑO } \\
0,60 \mathrm{~m} \text { lámina de agua }\end{array}$ \\
\hline FASE I & $\mathrm{CN}-1$ & $73,37 \mathrm{~km}$ & $0,18 \%$ & 8,26 & 14,38 \\
\hline & & & TOTAL FASE I & $16,52 \mathrm{Mm}^{3} / \mathrm{ANNO}$ & $28,76 \mathrm{Mm}^{3} /$ AÑO \\
\hline \multirow[b]{2}{*}{ FASE II } & $\mathrm{CN}-1$ & $73,37 \mathrm{~km}$ & $0,18 \%$ & 8,26 & 14,38 \\
\hline & $\mathrm{C}-1$ & $95,6 \mathrm{~km}$ & $0,15 \%$ & 7,54 & 13,15 \\
\hline & & & TOTAL FASE II & $23,08 \mathrm{Mm}^{3} /$ AÑO & $40,18 \mathrm{Mm}^{3} /$ AÑO \\
\hline \multirow{4}{*}{ FASE III } & $\mathrm{C}-3$ & $148,46 \mathrm{~km}$ & $0,21 \%$ & 8,92 & 15,55 \\
\hline & C-4 & $125,56 \mathrm{~km}$ & $0,33 \%$ & 11,19 & 19.49 \\
\hline & C-5 & $45,30 \mathrm{~km}$ & $0,44 \%$ & 12,93 & 22,49 \\
\hline & $\mathrm{CN}-1 \mathrm{Bis}$ & $20,13 \mathrm{~km}$ & $0,15 \%$ & 8,26 & 14,38 \\
\hline
\end{tabular}

Datos: R. Matías.

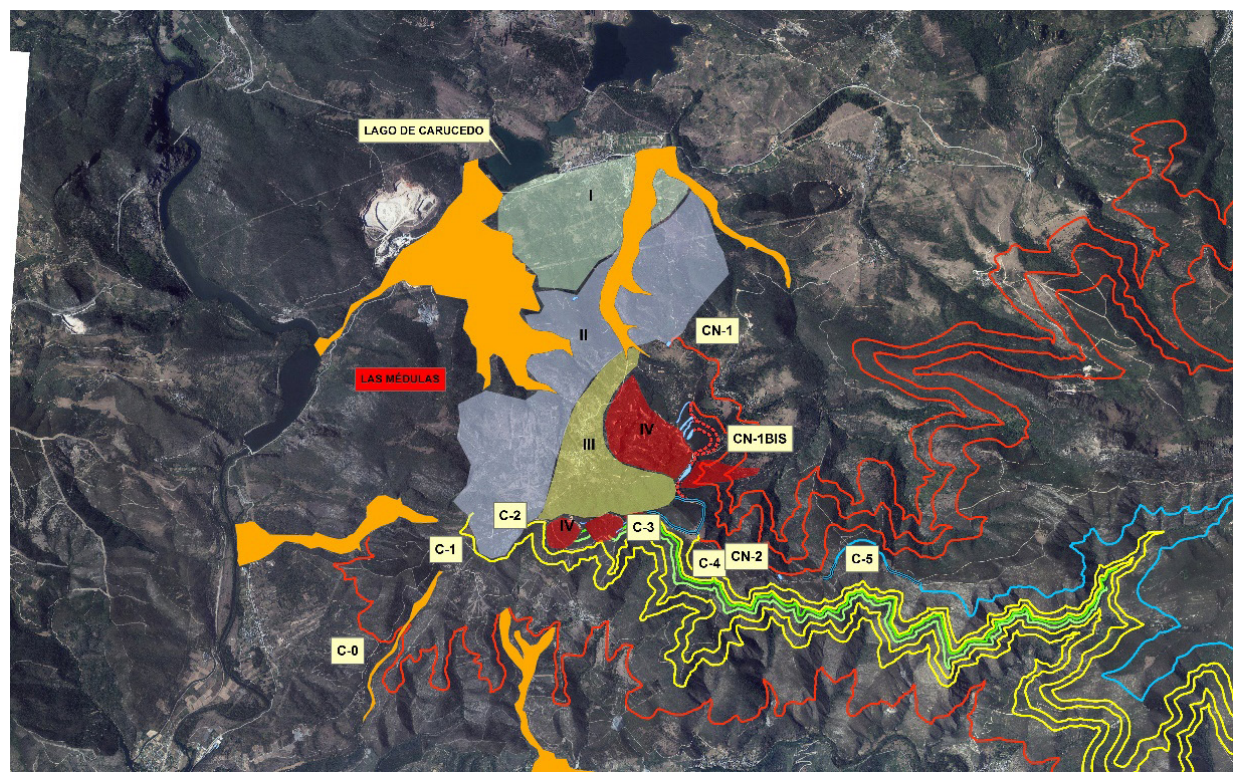

Figura n. ${ }^{\circ}$ 10: Llegada de los canales a Las Médulas y fases de explotación.

En naranja las acumulaciones de estériles. La fase IV (rojo) es la última que se trabajó, abandonando los romanos la explotación por agotamiento. Ortoimagen: PNOA 2017 cedida por el Instituto Geográfico Nacional. Información gráfica: R. Matías. 
ROBERTO MATÍAS RODRÍGUEZ

LOS CANALES DE LAS MÉDULAS (LEÓN-ESPAÑA): RAZONES PARA SU INCLUSIÓN EN EL PATRIMONIO...

\section{ESTADO DE CONSERVACIÓN}

Tras el cese de la explotación minera en Las Médulas, irremediablemente los canales pierden su función y se abandonan los trabajos de mantenimiento. El progresivo deslizamiento de la capa superficial de las laderas y la invasión por la vegetación los han ido aterrando y ocultando en numerosos puntos, si bien la naturaleza no ha sido capaz de borrar completamente la huella que Roma ha dejado en estos montes y siempre, aunque no lo parezca, es posible apreciar al menos una leve ondulación del terreno por donde hace 2000 años se conducían las aguas de ríos caudalosos.

No obstante, a pesar del tiempo transcurrido, el principal enemigo de esta gran obra de ingeniería es la actividad humana en forma de trabajos agrícolas, trazado de pistas y captaciones, repoblaciones forestales, explotaciones mineras, etc., especialmente cuando se emplea maquinaria pesada. La actividad agrícola secular ha llegado a desdibujar considerablemente el trazado de los canales en la proximidad de las poblaciones, que han crecido rodeadas de extensiones significativas de cultivos. En contraprestación, muchas de estas poblaciones se han aprovechado de los canales para establecer un amplio sistema de comunicación para su servicio, previniendo así la acción de la naturaleza.

Más graves resultan los daños producidos por las repoblaciones forestales, algunas realizadas en décadas pasadas, que han destruido completamente el trazado de diversos tramos tras la roturación del suelo con maquinaria pesada, incluso en el mismo entorno de Las Médulas. Lo mismo acontece con la actividad minera, principalmente canteras de pizarra, tanto en las zonas de extracción como en el emplazamiento de las escombreras de estériles.

A pesar de las observaciones anteriores, más del $85 \%$ del trazado de los canales es perfectamente reconocible sobre el terreno y forman parte de un paisaje secular de indudable valor (Fig. 11). Encontramos también notables ejemplos de tramos de canal perfectamente conservados, como ocurre en el singular entorno de la localidad de Llamas de Cabrera, donde podemos apreciar en toda su extensión la magnitud de esta obra hidráulica en las grandes paredes de piedra cortadas a pico mientras transitamos seguros por el canal romano al borde de enormes precipicios, recordando las palabras de Plinio:

Quienes hacen los cortes están colgados con cuerdas, de modo que a quien observa de lejos ni siquiera le parecen animales salvajes, sino pájaros. Suspendidos en el aire, nivelan y trazan las líneas del recorrido en su mayor parte, y se canalizan las aguas por donde no hay lugar para las pisadas del hombre. 


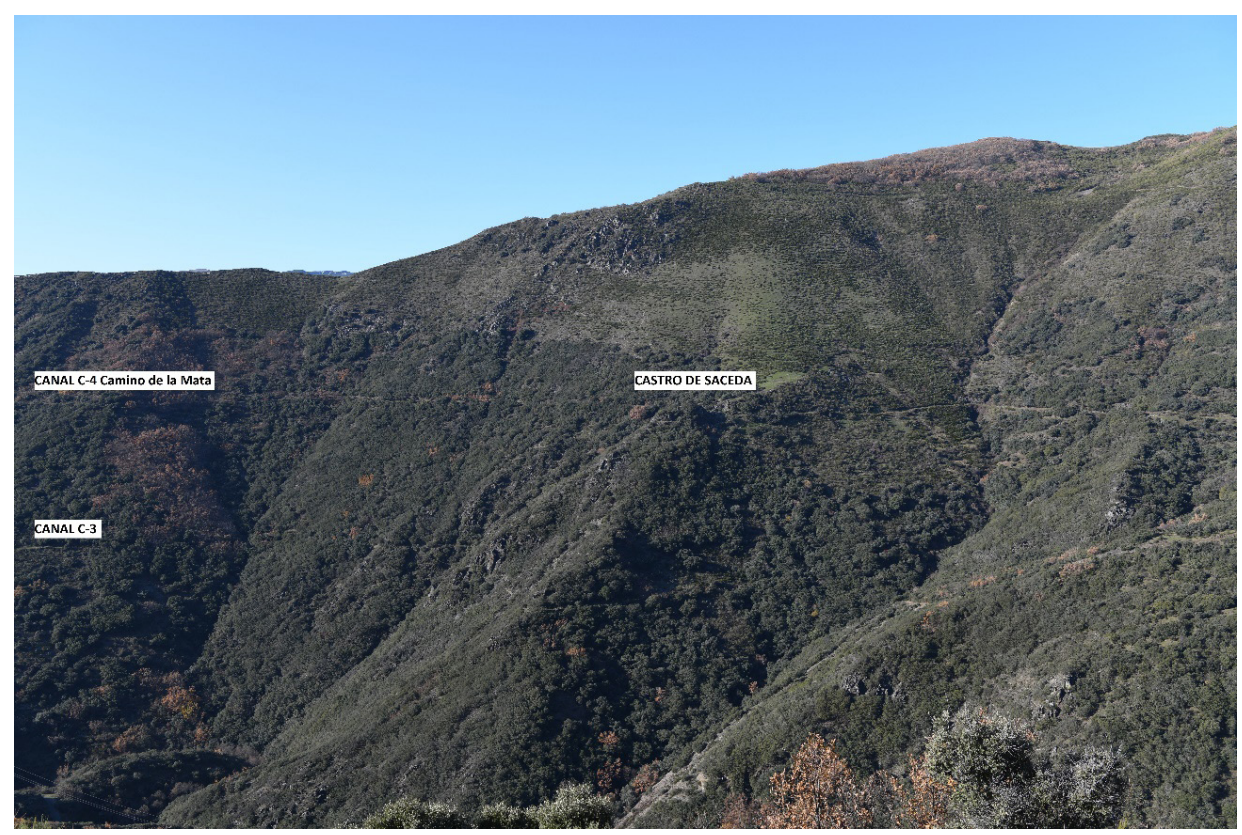

Figura n. ${ }^{\circ}$ 11: Vista de los canales C-3 y C-4 en el valle de Río Cabo con indicación de la ruta de senderismo Camino de La Mata. Foto: R. Matías.

\section{INTERVENCIONES DE PUESTA EN VALOR}

Tradicionalmente, siglos después del cese de la actividad minera en Las Médulas, diversos tramos de los canales se fueron convirtiendo paulatinamente en caminos, denominados popularmente en la zona como "carriles", permaneciendo algunos de ellos en actividad hasta bien entrado el siglo XX. Los cambios tecnológicos y las nuevas necesidades de transporte han transformado este territorio y dieron lugar al trazado actual de las principales vías de comunicación, por lo que la funcionalidad de los "carriles» quedó relegada a un segundo término o, simplemente, abandonada y olvidada, todo ello espoleado por la constante despoblación que se ha producido en esta zona de la geografía española a lo largo del siglo XX.

En los últimos años, promovidos principalmente por iniciativas de entidades locales y comarcales, que se están volcando en el turismo como alternativa a la minería de la pizarra y otras actividades agroganaderas, se han realizado diversas intervenciones para la recuperación de los canales como rutas de senderismo (Fig. 12), a la vez que se han efectuado algunas actuaciones arqueológicas en varios puntos: 
- $\quad$ Llamas de Cabrera (1997; 2003): recuperación y señalización de un tramo de $3 \mathrm{~km}$ del canal C-1 con diversas intervenciones arqueológicas en la caja del canal como limpieza y reconstrucción de taludes.

- Médulas-Llamas de Cabrera (2013-14): recuperación y señalización de una ruta por los canales entre Las Médulas y Llamas de Cabrera (Fig. 13) con un recorrido transitable de $63 \mathrm{~km}$ que pone en valor tanto los canales como otros elementos culturales de la zona (www.canalesromanos.es).

- San Pedro de Montes-San Adrián (2015-16): recuperación como ruta de senderismo de diversos tramos de los canales CN-1 y CN-2 entre las localidades de Peñalba de Santiago y San Clemente de Valdueza.

- Corporales-Saceda (2019): recuperación y señalización del Camino de La Mata entre las localidades de Corporales y Saceda $(14,5 \mathrm{~km}) .12 \mathrm{~km}$ de esta ruta discurren por el trazado del canal C-4. Se realizó también la excavación arqueológica de $230 \mathrm{~m}$ del canal C-4 en el Puerto de Peña Aguda (Corporales) y se limpió el foso y acondicionaron los accesos al Castro de Saceda.

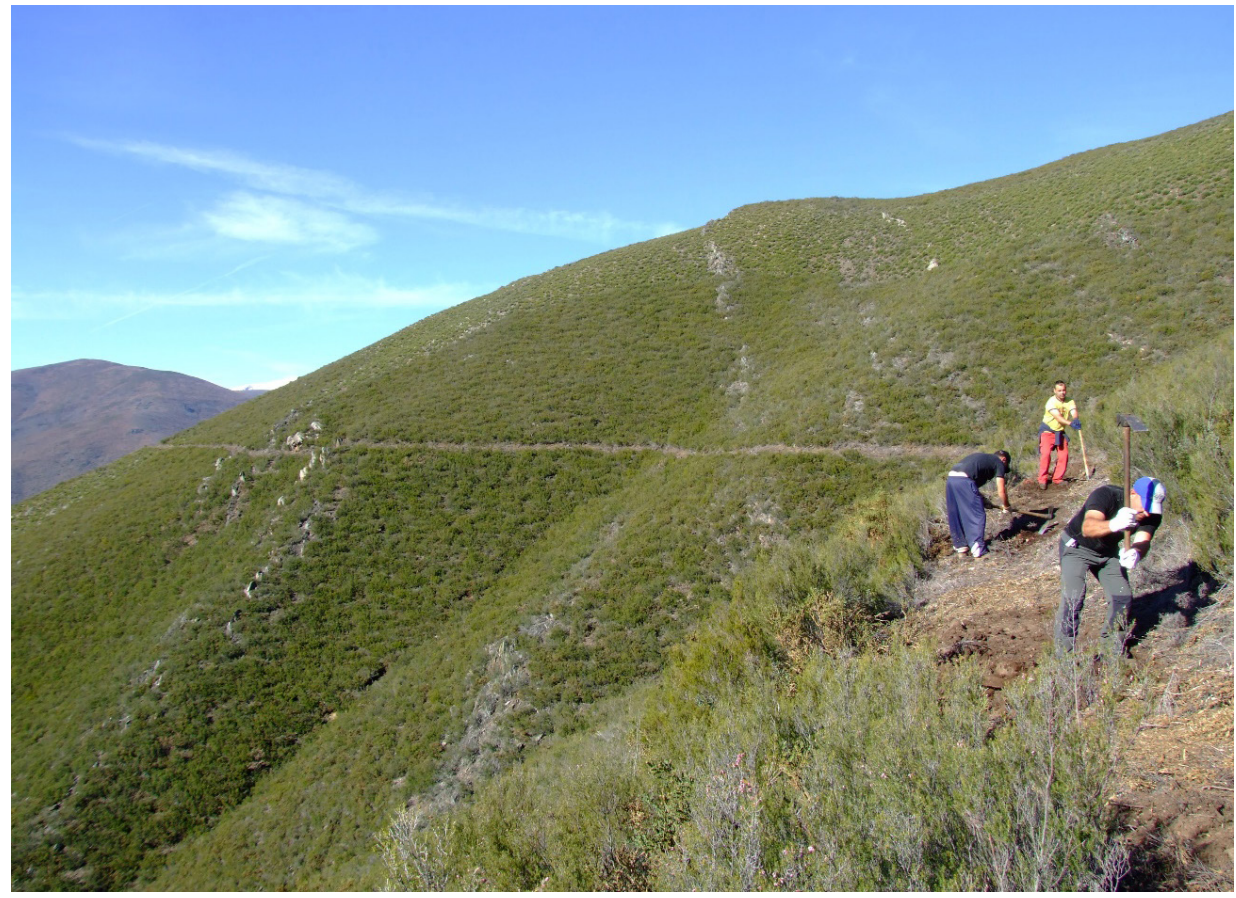

Figura n. ${ }^{\circ}$ 12: Trabajos de recuperación del canal C-5 como ruta de senderismo en el valle Lleiroso de Llamas de Cabrera. Foto: R. Matías. 
En estos momentos se está planteando por varias entidades locales diversos proyectos para la continuidad de la puesta en valor de este elemento patrimonial en sus diversos municipios, como es la unión física por una gran ruta de senderismo entre Las Médulas y la localidad de Corporales. La red hidráulica de Las Médulas vertebra un enorme territorio de más de $700 \mathrm{~km}^{2}$ en las comarcas del Bierzo y La Cabrera, cuya puesta en valor es percibida por sus habitantes como uno de los ejes principales de desarrollo para estos apartados lugares en franca recesión poblacional.

Asimismo, se está poniendo en marcha actualmente un proyecto financiado por la Diputación de León para redactar el documento de solicitud a la UNESCO del reconocimiento como Geoparque de todo el territorio de Las Médulas y su entorno, que incluye los canales y la minería del área del Teleno, donde se encuentra el mayor conjunto mundial de minería aurífera romana: Geoparque Médulas-Teleno.

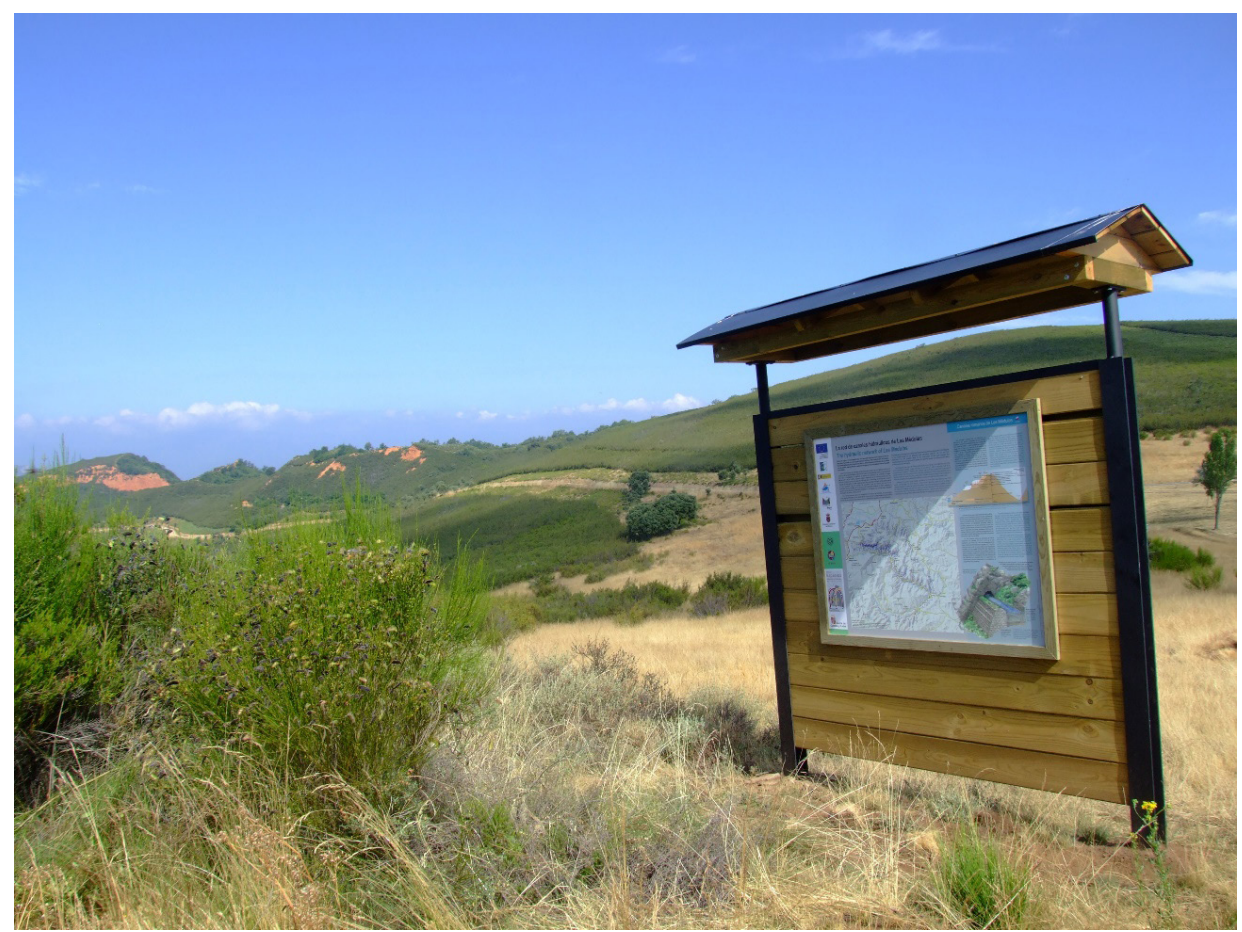

Figura n. ${ }^{\circ}$ 13: Cartel informativo del inicio de la ruta de los canales en Las Médulas (www.canalesromanos.es). Foto: R. Matías. 
ROBERTO MATÍAS RODRÍGUEZ

LOS CANALES DE LAS MÉDULAS (LEÓN-ESPAÑA): RAZONES PARA SU INCLUSIÓN EN EL PATRIMONIO...

\section{CONCLUSIONES}

Una vez expuestos los datos anteriores sobre el trazado y capacidad de suministro, queda en evidencia que la red de canales de abastecimiento de Las Médulas es una de las mayores obras de ingeniería hidráulica de la Antigüedad y una extraordinaria muestra del desarrollo tecnológico alcanzado por el Imperio Romano en este campo, como también demostraron en el abastecimiento de agua potable a las ciudades. El desconocimiento hasta fechas recientes de la magnitud, estructura e importancia de esta red hidráulica fue determinante para que en el momento de la declaración de Las Médulas como Patrimonio de la Humanidad (Diciembre 1997), quedase completamente relegada al olvido. Sin embargo, la existencia de este singular paraje de origen antrópico es el resultado final de su construcción exitosa; y es que, sin agua, no hubiera sido posible la explotación minera de este gigantesco yacimiento aurífero.

Desde el punto de vista histórico, el análisis topográfico preciso de los canales de Las Médulas confirma interesantes aspectos recogidos en el texto de Plinio El Viejo, cuya obra Naturalis Historia es el principal referente de los textos antiguos que se conserva en el ámbito de la minería aurífera romana. La posible existencia de los canales de "100 millas de distancia» que menciona Plinio en su texto era considerado utópico hasta el año 2004. Pero ahora sabemos que esta es una realidad firmemente constatable sobre el terreno.

Atendiendo a las circunstancias y características del canal más largo (C-3), de $148 \mathrm{~km}$ de trazado, con una pendiente precisa y uniforme del 0,3\%, quedamos maravillados cómo, hace 2000 años, un ingeniero pudo ordenar su construcción desde una cota concreta de la explotación de Las Médulas, alcanzando con éxito su objetivo sin tener que corregir su trazado, apurando al límite las posibilidades de suministro de agua del río Cabrera (Fig. 14). El canal inmediato (C-4) tuvo que ir a buscar el agua más arriba, captándola ahora en otra cuenca hidrográfica, lo que constituye el primer trasvase de cuencas de la Península Ibérica.

La realidad de Las Médulas es inseparable de aquello que hizo posible que hoy podamos admirar el ingenio desarrollado por el Imperio Romano en su empeño de dominar la naturaleza y ponerla a su servicio. Los canales constituyen un legado patrimonial de primer orden que no puede ser olvidado ni infravalorado respecto a Las Médulas, puesto que en ellos reside la verdadera historia y esencia de esta excepcional mina romana.

Este reconocimiento y la conservación-puesta en valor de los canales de Las Médulas es una deuda que tenemos con las generaciones futuras, tras décadas de abandono y desidia injustificados. Sin ninguna duda, estamos ante «una importante obra destacada de la creatividad humana», que fue el primer criterio aplicado por la UNESCO para la declaración de Las Médulas como Patrimonio de la Humanidad en 1997. 


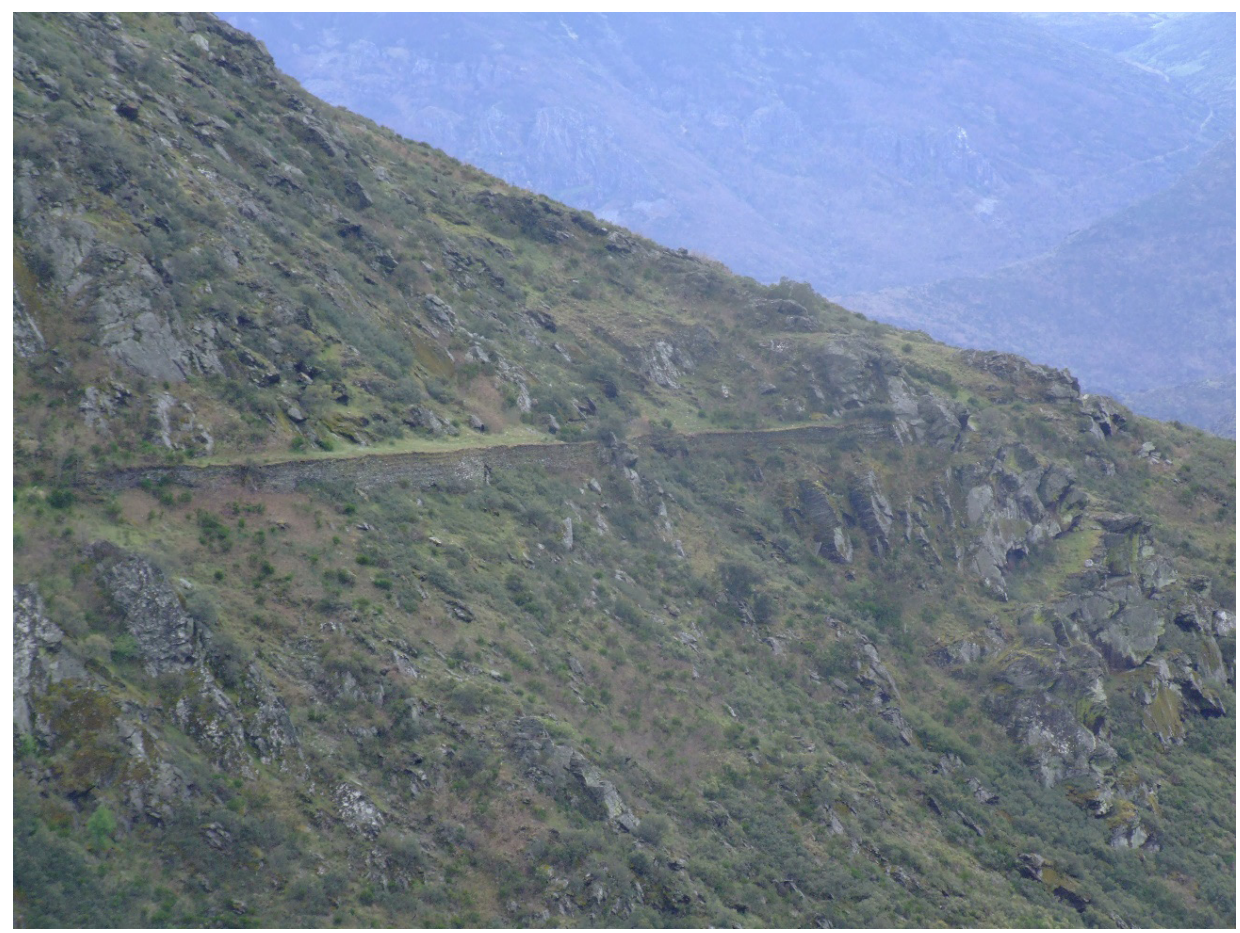

Figura n. ${ }^{\circ}$ 14: Muros de sostenimiento del canal C-3 en las inmediaciones de la Ermita de la Virgen del Valle (Llamas de Cabrera). Foto: R. Matías.

\section{REFERENCIAS BIBLIOGRÁFICAS}

Prado, C. (1862). Reseñas geológicas de la provincia de Avila y de la parte occidental de la de León. Madrid: Imprenta Nacional.

Domergue, C. (1972-74). A propos de Pline et pour illustrer sa description des mines d'or romaines d'Espagne. Archivo Español de Arqueología, 45-47, pp. 499-548.

Domergue, C. (1987). Catalogue des mines et fonderies antiques de la Péninsule Ibérique. Madrid: Editorial de la Casa de Velázquez, Série Archéologie, 8, (2) (Vol. I, 244 p.; Vol. II, 117 p.).

Domergue, C. (2008). Les mines antiques: la production des métaux aux époques grecque et romaine. Paris: Picard.

Domergue, C. (2012). Les exploitations hydrauliques romaines dans les dépôts alluviaux aurifères du Nord-Ouest de l'Espagne: Las Médulas et le Teleno (Province de León). À propos de publications récentes. En J.-P. Bost (dir), L'eau: usages, risques et représentations dans le Sud-Ouest de la Gaule et le Nord de Péninsule Ibérique, de la fin de l'âge du Fer à l'Antiquité tardive (II s.a.C-VI s.p.C.). Aquitania Supplement 21, pp. 111-140. Bordeaux. 
ROBERTO MATÍAS RODRÍGUEZ

LOS CANALES DE LAS MÉDULAS (LEÓN-ESPAÑA): RAZONES PARA SU INCLUSIÓN EN EL PATRIMONIO...

Fernández-Posse, M. D., Sánchez-Palencia, F. J. (1988). La Corona y el Castro de Corporales II. Campaña de 1983 y prospecciones en la Valdería y La Cabrera (León). Madrid: Ministerio de Cultura, Dirección general de Bellas Artes y Archivos.

Forchheimer, P. (1935). Tratado de Hidráulica. Buenos Aires: Labor.

Gil y Carrasco, E. (1843). Bosquejo de un viaje a una provincia del interior. Madrid: Facsimil de Breviarios de la Calle del Pez. Edición de María Paz Díez Taboada.

Gómez Moreno, M. (1925-26). Catálogo monumental de España: la provincia de Léon. 2 Tomos. Madrid.

González, M. L., Matías, R. (2013). Yacimientos primarios de oro en Omañas (León-España): minas y canales en el Valle Gordo. Actas del XIV Congreso sobre Patrimonio Geológico y Minero. Castrillón (Asturias), pp. 583-602.

Gómez Núnez, S. (1925): El general de artillería Don Juan Manuel Munárriz y la siderurgia del siglo XVIII en la región del Bierzo. Madrid: Publicaciones de la Real Sociedad Geográfica.

King, H. W., Brater, E. F. (1962). Manual de Hidráulica. México: Uteha.

Liria Montañes, J. (2001). Canales hidráulicos: proyecto, construcción, gestión y modernización. Madrid: Colegio de Ingenieros de Canales, Caminos y Puertos. Colección Seinor.

López, D. G. (1980). Las Médulas. León: Nebrija.

López, D. G. (1996). Las Médulas. León: Edilesa.

López, D. G. (2005). Minas de oro romanas: Las Médulas. León: Edilesa.

López, L. (1997). Manual de Hidráulica. Alicante: Textos Docentes. Universidad de Alicante.

Martins, C. M. B. (2008). A exploraçao mineira romana e a metalurgia do ouro em Portugal. Cadernos de Arqueologia. Monografias, 14. Braga: Universidade do Minho. Instituto de Ciencias Sociais.

Matías, R. (2004). Ingeniería minera romana: La red hidráulica de Las Médulas. Actas del II Simposio de Minería y Metalurgia Antiguas del Sudoeste Europeo. Madrid, pp. 279-293.

Matías, R. (2006). La Red Hidráulica de Las Médulas: trazado e ingeniería. Revista del Instituto de Estudios Bercianos, 30-31, pp. 5-85.

Matías, R. (2006a). Las Médulas: ingeniería minera romana. León: Universidad de León.

Matías, R. (2006b). La minería aurífera romana del Noroeste de Hispania: Ingeniería Minera y Gestión de las explotaciones auríferas romanas en la Sierra del Teleno. En Nuevos Elementos de Ingeniería, Actas del III Congreso de las Obras Públicas Romanas. Salamanca, pp. 213-263.

Matías, R. (2008). El complejo de minería aurífera romana de Llamas de Cabrera (León). Revista de Instituto de Estudios Bercianos, 32-33.

Matías, R. (2008a). La red hidráulica de Las Médulas: una excepcional obra de la ingeniería romana. Actas del Homenaje a Las Médulas de la Real Academia Española de la Ingeniería. En prensa.

Matías, R. (2008b). Nuevos hallazgos en la mina aurífera romana de Llamas de Cabrera (León-España) y su relación con la cronología de la actividad minera en Las Médulas. Actas del V Simposio sobre Historia de la Minería y Metalurgia en el Suroeste Europeo. Lleida:. SEDPGYM, pp. 513-528.

Matías, R. (2008c). El agua en la ingeniería de la explotación minera de Las Médulas (LeónEspaña). Lancia, 7, pp. 17-112.

Matías, R. (2012). Nuevos datos para el conocimiento de la minería de oro romana en el Alto Carrión (Palencia-España). Colección de Historia: Montaña Palentina, 6, pp. 11-49. 
ROBERTO MATÍAS RODRÍGUEZ

LOS CANALES DE LAS MÉDULAS (LEÓN-ESPAÑA): RAZONES PARA SU INCLUSIÓN EN EL PATRIMONIO...

Matías, R. (2013). Minería aurífera romana en el área Salientes-Villablino (León-España). En Actas del XIV Congreso Internacional sobre Patrimonio Geológico y Minero, CastrillónAsturias, pp. 631-648.

Matías, R. (2016). Las Médulas (León-España): revisión e incógnitas sobre la tecnología minera romana de la mayor explotación del Mundo Antiguo. Actas del XI International Mining History Congress (IMHC2016), Linares, pp. 235-244.

Matías, R. (2014). La minería del oro en el Imperio Romano y su puesta en valor: contextualización e importancia de la minería aurífera romana en el área Valongo-Paredes. Actas del 1. ${ }^{\circ}$ Congresso Minerãçao Romana em Valongo. Valongo-Portugal: Edición digital, pp. 3-39. http://www.altorelevo.org/cmr/pdf/Atas_1oCongressoMineracaoRom anaValongo2014.pdf

Matías, R. (2017). Cartografía de un nuevo tramo de $43 \mathrm{~km}$ del canal C-4 de la mina de oro romana de Las Médulas (León-España). Actas del XVII Congreso Internacional sobre Patrimonio Geológico y Minero. Madrid: Cuadernos del Museo Geominero, 29, pp. 327-340.

Matías, R. (2017A). Hallazgo de minería aurífera romana en el Paraje del Morredero (Sierra del Teleno. León-España). Actas del XVII Congreso Internacional sobre Patrimonio Geológico y Minero. Madrid: Cuadernos del Museo Geominero, 29, pp. 341-349.

Matías, R. (2019). Agua y canales en la minería hidráulica romana del oro. Actas del VI Congreso Internacional de Ingeniería Romana. Santo Domingo de La Calzada (La Rioja).

Matías, R. (2020). Minería hidráulica romana en Los Ancares Leoneses. En prep.

Matías, R., Fonte, J., Lima, A., Monteiro, A., Granda, V., Moutihno, J., Silva, J., Aguiar, P. (2014). Evidencias de minería hidráulica romana en la Sierra de Pías (Valongo-Portugal). Actas del XV Congreso Internacional sobre Patrimonio Geológico y Minero. Logrosán, pp. 481-498.

Matías, R., González-Nistal, S. (2014). Delimitación de un nuevo y extenso yacimiento aurífero primario en la sierra del Teleno (León-España) siguiendo las evidencias de minería romana. En Actas del XV Congreso Internacional sobre Patrimonio Geológico y Minero. Logrosán, pp. 519-542.

Matías, R. (2014a). Minería aurífera romana en el campo filoniano Lucillo-Villalibre. Sierra del Teleno (León-España). En Actas del XV Congreso Internacional sobre Patrimonio Geológico y Minero. Logrosán, pp. 499-518.

Matías, R., Llamas, B. (2017). Use of LIDAR and photointerpretation to map the water supply at the Las Murias-LosTallares Roman gold mine (Castrocontrigo, León, Spain). Archaeological Prospection.25, pp. 59-69. John Wiley \& Sons, Ltd.

Matías, R., Llamas, B. (2020). Roman Gold Mining at "Las Miédolas»: LIDAR and photointerpretation in the analysis of "peines" system. En prep.

Moreno, I. (2004). Topografía Romana. Elementos de Ingeniería Romana, Actas del II Congreso Europeo Las Obras Públicas Romanas. Tarragona, pp. 157-189.

Moreno, I. (2015). Análisis técnico y constructivo del acueducto romano de Albarracín a Cella. Las técnicas y las construcciones en la ingeniería romana. Actas del V Congreso Europeo de las Obras Públicas Romanas, pp. 225-248.

Perea, A., Sánchez-Palencia, F. J. (1995). Arqueología del oro Astur: orfebrería y minería. Caja Asturias.

Pérez-García, L. C. (2001). La mina de oro romana de Las Médulas. Patrimonio Geológico de Castilla y León. Madrid: ENRESA, pp. 30-55. 
Pérez, M., Matías, R. (2008). Plinio y la minería aurífera romana: nueva traducción e interpretación de Plin. Nat. 33.66-78. Cuadernos de Filología Clásica. Estudios Latinos, 28, (1), pp. 43-58.

Sáenz, C., Vélez, J. (1974). Contribución al estudio de la minería primitiva del oro en el Noroeste de España. Madrid: Ediciones Atlas.

Sánchez-Palencia, F. J. (1980). Prospecciones en las explotaciones auríferas del N.O. de España (Cuencas de los ríos Eria y Cabrera y Sierra del Teleno). Noticiario Arqueológico Hispánico, 8, pp. 214-289.

Sánchez-Palencia, F. J., Pérez, L. C. (2000). La infraestructura hidráulica: canales y depósitos. En Sánchez-Palencia, F. J. (ed). (2000): Las Médulas (León). Un paisaje cultural en la "Asturia Augustana". León: Instituto Leonés de Cultura, pp. 189-207.

Sánchez-Palencia, F. J., Sastre, I. (2002). La red hidráulica en las minas romanas de oro del noroeste hispano. En ARTIFEX Ingeniería Romana en España. Museo Arqueológico Nacional. Madrid: Catálogo de la exposición, pp. 251-254.

Sánchez-Palencia, F. J., Sastre, I. (2015). El oro de Las Médulas. Historia-National Geographic. 
